\title{
Surface Modification of Acetaminophen Particles by Atomic Layer Deposition
}

\section{Kääriäinen, Tommi Olavi}

2017-06-15

Kääriäinen , T O , Kemell , M L , Vehkamäki , M J , Kääriäinen , M-L , Correia , A , Almeida Santos, H , Marques dos Santos Bimbo , L M , Hirvonen , J T , Hoppu , P , George , S M , Cameron , D C , Ritala , M K \& Leskelä , M A 2017 , ' Surface Modification of Acetaminophen Particles by Atomic Layer Deposition ' , International Journal of pÿPharmaceutics , vol. 525 , no. 1 , pp. 160174 . https://doi.org/10.1016/j.jjpharm.2017.04.031

http://hdl.handle.net/10138/307765

https://doi.org/10.1016/j.jpharm.2017.04.031

cc_by_nc_nd

acceptedVersion

Downloaded from Helda, University of Helsinki institutional repository.

This is an electronic reprint of the original article.

This reprint may differ from the original in pagination and typographic detail.

Please cite the original version. 


\section{Surface Modification of Acetaminophen Particles by}

\section{Atomic Layer Deposition}

Tommi O. Kääriäinen ${ }^{a, b, d, ~}{ }^{*}$, Marianna Kemell ${ }^{a}$, Marko Vehkamäki ${ }^{a}$, Marja-Leena Kääriäinen

b, d, Alexandra Correia ${ }^{c}$, Hélder A. Santos ${ }^{c}$, Luis M. Bimbo ${ }^{c}$, Jouni Hirvonen ${ }^{c}$, Pekka Hoppu ${ }^{d}$, Steven M. George ${ }^{b}$, David C. Cameron ${ }^{e}$, Mikko Ritala ${ }^{a}$, and Markku Leskelä ${ }^{a}$

${ }^{a}$ Laboratory of Inorganic Chemistry, University of Helsinki, P.O. Box 55 (A.I.Virtasen aukio 1), FI-00014 Helsinki, Finland. Email: tommi.kaariainen@helsinki.fi

${ }^{\mathrm{b}}$ Department of Chemistry and Biochemistry and Department of Chemical and Biological Engineering, University of Colorado, Boulder, Colorado 80309

${ }^{c}$ Division of Pharmaceutical Chemistry and Technology, Faculty of Pharmacy, University of Helsinki, FI-00014 Helsinki, Finland

${ }^{\mathrm{d}}$ NovaldMedical Ltd Oy, Telkäntie 5, 82500 Kitee, Finland

${ }^{\mathrm{e}}$ R\&D Centre for Low-Cost Plasma and Nanotechnology Surface Modification, Masaryk University, Kotlářská 267/2, 61137 Brno, Czech Republic.

*Corresponding Author: Laboratory of Inorganic Chemistry, University of Helsinki, P.O. Box 55 (A.I.Virtasen aukio 1), FI-00014 Helsinki,Finland. Email: tommi.kaariainen@helsinki.fi. Phone: +17207576020 . 


\section{ABSTRACT}

Active pharmaceutical ingredients (APIs) are predominantly organic solid powders. Due to their bulk properties many APIs require processing to improve pharmaceutical formulation and manufacturing in the preparation for various drug dosage forms. Improved powder flow and protection of the APIs are often anticipated characteristics in pharmaceutical manufacturing. In this work, we have modified acetaminophen particles with atomic layer deposition (ALD) by conformal nanometer scale coatings in a one-step coating process. According to the results, ALD, utilizing common chemistries for $\mathrm{Al}_{2} \mathrm{O}_{3}, \mathrm{TiO}_{2}$ and $\mathrm{ZnO}$, is shown to be a promising coating method for solid pharmaceutical powders. Acetaminophen does not undergo degradation during the ALD coating process and maintains its stable polymorphic structure. Acetaminophen with nanometer scale ALD coatings shows slowed drug release. ALD $\mathrm{TiO}_{2}$ coated acetaminophen particles show cytocompatibility whereas those coated with thicker $\mathrm{ZnO}$ coatings exhibit the most cytotoxicity among the ALD materials under study when assessed in vitro by their effect on intestinal Caco-2 cells.

\section{KEYWORDS}

Atomic layer deposition, acetaminophen, drug release, cytocombatibility, drug delivery system 


\section{ABBREVIATIONS}

ALD, atomic layer deposition ; API, active pharmaceutical ingredient; ATP, adenosine triphosphate; ATR-FTIR, attenuated total reflectance Fourier transmittance infrared; DCF-DA , dichlorofluorescin diacetate; DEZ, diethylzinc; DMEM, Dulbecco's modified Eagle's medium; DSC, Differential scanning calorimetry; EDTA-PBS, ethylenediamine tetraacetic acid- phosphate buffered saline; FIB-SEM, focused ion bean scanning electron microscope; HBSS, Hank's Balanced Salt Solution; HIFBS, heat inactivated fetal bovine serum; HPLC, high performance liquid chromatography; ICP-MS, inductively coupled mass spectrometry; PBS, phosphate buffered saline; PLGA, poly(lactid-co-glycolic acid); ROS, reactive oxygen species; SD, standard deviation; SEM-EDS, scanning electron microscope with energy dispersive X-ray spectroscopy; TGA, thermogravimetric analysis; TiCl4, titanium tetrachloride; TMA, trimethylaluminum; TNF-

$\alpha$, tumor necrosis factor alpha; TTIP titanium(IV)isopropoxide; XRPD, X-Ray powder diffraction; Wt, weight. 


\section{INTRODUCTION}

Primary drug particles in powder form which comprise active pharmaceutical ingredients (APIs) are typically solid organic particles. Drug powders are used to create enteral drug dosage forms (such as tablets, capsules, pellets and granules), inhalation powders, parenteral injectable preparations, topical transdermal patches and emulsions, as well as ophthalmic systems such as contact lenses and eye drops. Pharmaceutical manufacturing can benefit from improved surface characteristics of powders that optimize drug loading efficiency and improve powder processability (Ghoroi et al., 2013; Shi and Sun, 2011; Vanhoorne et al., 2014; Ehlers et al., 2009; Sauer et al., 2013; Jallo et al., 2015; Beach et al., 2010). Quite often there is a need to stabilize the desired solid state of the API. These can be amorphous or hydrate states, which make the pharmaceutical processing hard to perform unless the drug powders are coated (Airaksinen et al., 2005; Han and Suryanarayanan, 1999; Matsuo and Matsuoka, 2007; Wu et al., 2011). The coating may also provide chemical stabilization for the pharmaceutical (Wu et al., 2011) or control of the drug release (Chen et al., 2006). There are many biological interfaces, such as between nanoparticles and carbon nanotubes and APIs, where control of the surface characteristics of pharmaceutical powders can improve their therapeutic response and bioavailability (Terracciano et al., 2015; Taylor et al., 2014; Schäfer et al., 2013; Chow et al., 2007).

Usually, drug particles in powder form are in the size range of 1-200 $\mu \mathrm{m}$. Current drug development pursuing improved bioavailability of drug materials is based on the production of nanocrystals and this has reduced the drug particle size to 200-800 nm (Peltonen and Hirvonen, 2014; Sarnes et al., 2013). The most frequently used coating technique on drug powders today is spraying of atomized coating liquid into a fluidized powder bed (Behzadi et al., 2008). The 
atomization is usually obtained with high pressure air, electrostatics or ultra sound. Coating of small particles can be difficult, because the size of the individual coating liquid droplets is usually over $30 \mu \mathrm{m}$ (Ehlers et al., 2009; Werner et al., 2007). Spray-drying, a widely used operation in pharmaceutical manufacturing, is also used for particle encapsulation (Vanhoorne et al., 2014; Chow et al., 2007; Vehring, 2008; Dobry et al., 2009), in an attempt to overcome poor tabletability of pharmaceutical crystals (Shi and Sun, 2011; Vanhoorne et al., 2014), or to mask the undesired taste of the API (Shi and Sun, 2011). Spray drying is used to produce solid dispersions, which have already been investigated for some time for increasing the drug release rate and bioavailability of poorly water-soluble drugs, as well for controlling the drug release rate (Dobry et al., 2009; Giri et al., 2012; Huang and Dai, 2014). Dry-particle coating is an alternative method to spray drying where the addition of excipient particles is done by blending them with the API particles. Dry particle coating is favourable, for example, for moisture sensitive drugs since it does not involve the use of aqueous solvents. The removal of solvents from the final formulation is energyconsuming and complicates the process (Sauer et al., 2013; Jallo and Dave, 2015; Beach et al., 2010; Hoashi et al., 2013).

The maximum drug loading has been used in particle engineering to distinguish between particle coating and particle encapsulation. Coated drug particles have a core-shell structure and the maximum drug loading of the coated particles is usually above $50 \mathrm{wt}-\%$, preferably above $90 \mathrm{wt}-$ $\%$ (Chow et al., 2007). In order to increase the drug loading of conventional encapsulation methods, Singh et al. used pulsed laser deposition to create nanoscale ultra-thin films of poly(lactid-co-glycolic acid) (PLGA) on antiasthmatic budesonide particles. They did not report the film thickness on particles due to an inability to perform thickness estimation, resulting from the non-uniform nature of the particle surfaces (Singh et al., 2002). A modified spray drying 
method, which can be used both for drug particle synthesis and particle coating by physical vapour deposition, has been developed and studied for synthesizing drug particles (Eerikäinen et al., 2003), for coating salbutamol sulfate particles with L-leucine (Raula et al., 2008), for encapsulating indomethacin nanocrystals in mannitol microparticles with an L-leucine coating (Laaksonen et al., 2011), and for combining budesonide and salbutamol in microparticles coated with L-leucine (Raula et al., 2013; Vartiainen et al., 2016). In this method, APIs, binders and coating material are dissolved in water to form a precursor solution which is used in an aerosol process. The atomized solution mixed with nitrogen gas forms an aerosol which is introduced to a heated laminar flow reactor. In the reactor the solvent will be evaporated forming particles from the solute which will undergo further deposition by the evaporated coating substance (L-leucine) in the gas phase.

State-of-the-art drug processing requires well defined and controlled surface modification techniques. Novel drug delivery systems (Terracciano et al., 2015) are needed for the stabilization of acetaminophen nanocrystals in aqueous medium (Das et al., 2013), targeted drug delivery based on metal cation attachment to active pharmaceutical ligand forming coordination compounds (Ledeti et al., 2013), and biomedical imaging and molecular diagnostics (Park et al., 2010).

Because of the inhomogeneous nature of the surfaces and irregular shape of drug powder particles, current coating techniques usually fail to achieve smooth conformal coatings around particles, despite the rather large size of the original particle ( $>100 \mu \mathrm{m}$ in diameter). At present, there is a real need to obtain thin conformal coatings for small API particles. Novel ways to protect, modify and functionalize drug particles potentially provide remarkable improvements in the development and usage of pharmaceuticals. 
Atomic Layer Deposition (ALD) is a surface controlled, self-limiting layer-by-layer method for depositing thin films onto solid supports from the gaseous phase of the precursors. ALD is widely considered as a superior method for coating three-dimensional and porous substrates, and has gained an important and established role in the semiconductor industry and its development (George, 2010; Miikkulainen et al., 2013; Hyde et al., 2007; Johnson et al., 2014; Knez et al., 2006; Kääriäinen et al. 2013). The two most important advantages of ALD are excellent conformality and film thickness control at the sub-nanometer level. Each atomic layer formed in the sequential process is a result of saturated surface controlled chemical reactions. Commonly, in the growth of binary compounds, such as metal oxides, a reaction cycle consists of two reaction steps. In one step the metal compound precursor is allowed to react with the surface and become chemically bonded to it. In the next step the metal reacts with the oxygen precursor. Between the steps a purge is applied to remove any excess of precursor and the reaction by-products. This reaction cycle is repeated as many times as necessary to achieve the desired film thickness. The precursors form stoichiometric films with large area uniformity and conformality even on complex surfaces with deformities. Layer-by-layer growth allows one to change the material composition abruptly after each step (George, 2010; Miikkulainen et al., 2013). ALD producing conformal nanometer scale films is a well demonstrated method on various particles with different size and composition (Ferguson et al., 2000; Ferguson et al., 2004a; Ferguson et al., 2004b; Hakim et al., 2005; McCormick et al., 2007; King et al., 2008; Nevalainen et al., 2009; King et al., 2012; Longrie et al., 2014). Furthermore, ALD on powder substrates is scalable for manufacturing. Early development of ALD on particles utilized fluidized bed batch reactors which are well-established technologies in the pharmaceutical industry. The latest development in particle ALD has focused on continuous processing of particles following the trends in industrial powder processing (Van 
Ommen, 2010). It is suggested that pharmaceutical manufacturing can benefit from capabilities of ALD. Potential applications can be e.g. particle surface functionalization, stabilization of APIs, and improved bulk properties such as better powder flowability.

In this work, we have studied ALD on solid pharmaceutical particles by depositing conformal nanometer scale metal oxide films on particles of the drug acetaminophen. Acetaminophen is a widely used analgesic and antipyretic drug agent. In order to show the proof-of-concept for the application of ALD on API we have investigated the physicochemical characteristics after ALD coating, the drug dissolution, and cytotoxicity of ALD oxide coated acetaminophen.

\section{MATERIAL AND METHODS}

\subsection{Atomic layer deposition (ALD) on acetaminophen particles}

ALD on acetaminophen particles was carried out in a rotary ALD reactor as described by McCormick et al. 2007, shown in Figure 1, using static exposures of reactants at temperature around $100{ }^{\circ} \mathrm{C}$. The reactor assembly consisted of a stainless steel vacuum sealed main chamber with heater, vacuum pump and pump line separated from the vacuum chamber by a gate valve. A multiple-input flange for the dosing of reactants was connected to reactant sources controlled by pneumatic valves, and a magnetically coupled rotary manipulator rotated the porous reactor inside the main chamber to agitate the particles during the deposition. The main chamber volume was about $2.5 \mathrm{dm}^{3}$. Acetaminophen in powder form (Sigma-Aldrich, 98-101.0 \%) was used as received. ALD films were grown using as precursors trimethylaluminum (TMA) (Sigma-Aldrich, 98\%), titanium tetrachloride $\left(\mathrm{TiCl}_{4}\right)$ (Sigma-Aldrich, 98\%), titanium(IV)isopropoxide (TTIP) (Sigma-Aldrich, 99,999\%, trace metal basis), diethylzinc (DEZ) (Sigma-Aldrich, 98\%) and deionized water. $\mathrm{TMA}, \mathrm{TiCl}_{4}, \mathrm{DEZ}$ and water were vaporized from the source at a room 
temperature while TTIP was vaporized from the source at a temperature of 65 to $70{ }^{\circ} \mathrm{C}$. TTIPwater chemistry is a commonly used and studied process for ALD and allows the growth of $\mathrm{TiO}_{2}$ at low temperatures suitable for organic and temperature sensitive materials (King et al., 2008; Ritala et al., 1993; Aarik et al., 2000; Knez et al., 2006). TTIP-water chemistry is also favorable for avoiding $\mathrm{HCl}$ production, which is a byproduct of $\mathrm{TiCl}_{4}$-water $\mathrm{ALD}$ chemistry.

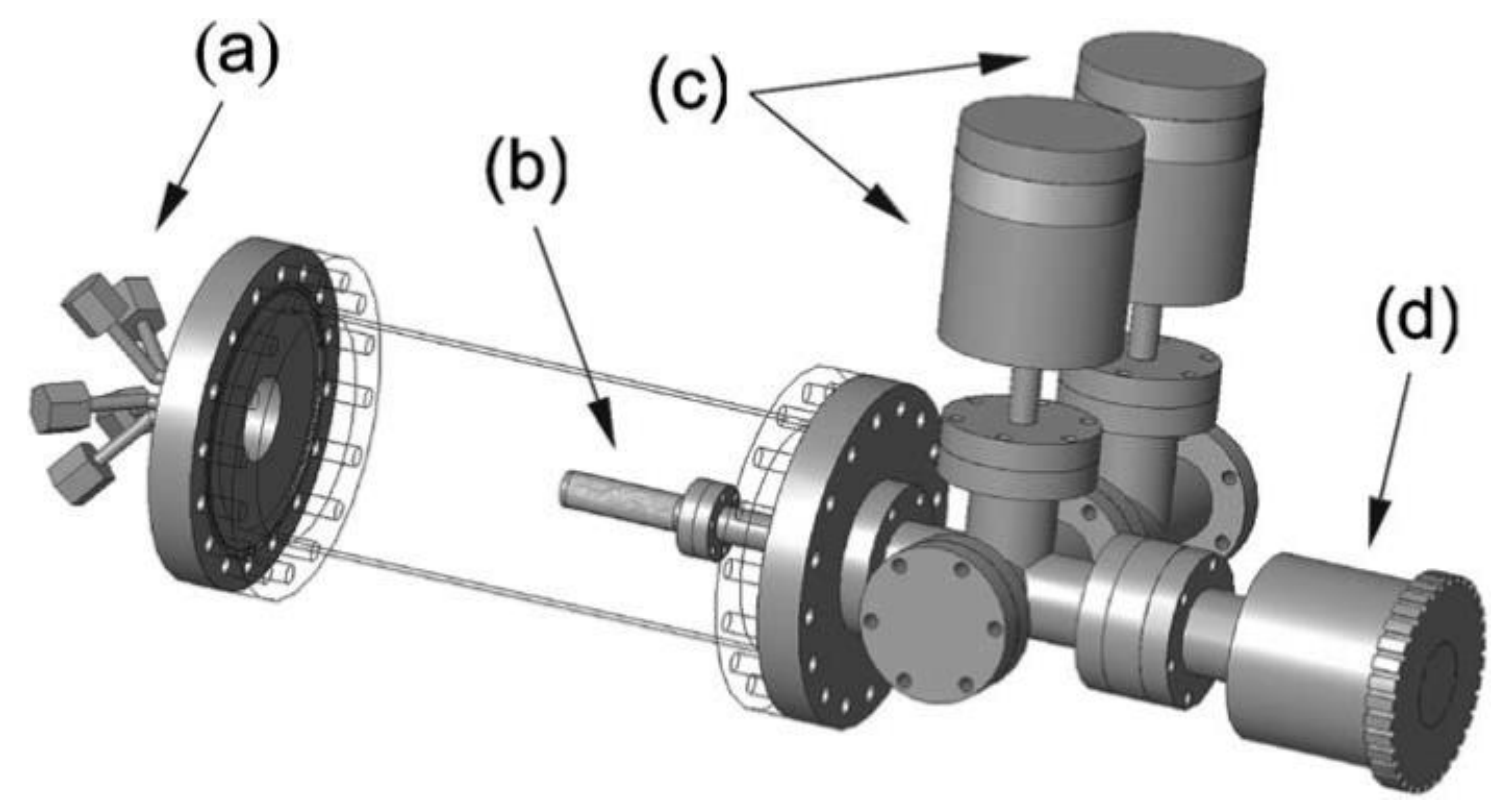

Figure 1. Schematic diagram of rotary ALD particle reactor with, a) multiple-input reactant dosing flange, b) small porous metal cylinder inside the main vacuum chamber, c) capacitance manometers to control the partial pressure, and d) magnetically coupled rotary manipulator to agitate particles inside metal cylinder during the deposition. Reprinted with permission from J. A. McCormick et al. 2007, J. Vac. Sci. Technol. A 25, 67 (C) 2007, American Vacuum Society.

The self-limiting surface reactions taking place in the deposition of ALD metal oxides are described in the literature for $\mathrm{TiO}_{2}$ using $\mathrm{TiCl}_{4}-\mathrm{H}_{2} \mathrm{O}$ chemistry (Ferguson et al., 2004a) or TTIP$\mathrm{H}_{2} \mathrm{O}$ chemistry (King et al., 2008), for $\mathrm{Al}_{2} \mathrm{O}_{3}$ using TMA- $\mathrm{H}_{2} \mathrm{O}$ chemistry (George, 2010), and for $\mathrm{ZnO}$ using DEZ $-\mathrm{H}_{2} \mathrm{O}$ chemistry (Elam and George, 2003). The reaction by-products other than isopropanol in the TTIP- $\mathrm{H}_{2} \mathrm{O}$ process have included acetone, propene, water and hydrogen (Rahtu and Ritala, 2002). 
The reactant exposure sequence for each ALD cycle was the following (McCormick et al., 2007): 1) exposure of metal precursor at a vapor pressure of 0.5 to 2 Torr, 2) hold for metal precursor reaction time, 3) pump out excess metal precursor and reaction products, 4) dose $\mathrm{N}_{2}$ at 10 to 20 Torr for purging the reactor, 5) pump out $\mathrm{N}_{2}, 6$ ) expose $\mathrm{H}_{2} \mathrm{O}$ at 1 to 2 Torr, 7) hold for $\mathrm{H}_{2} \mathrm{O}$ reaction time, 8) pump out excess $\mathrm{H}_{2} \mathrm{O}$ and reaction products, 9) dose $\mathrm{N}_{2}$ at 10 to 20 Torr for purging the reactor, and 10) pump out $\mathrm{N}_{2}$. The reaction times were between 60 to $240 \mathrm{~s}$. The pump out times used for the precursors were between 60 to $360 \mathrm{~s}$. The $\mathrm{N}_{2}$ exposure time was $60 \mathrm{~s}$ and pump out time for the $\mathrm{N}_{2}$ was $60 \mathrm{~s}$. After each reactant exposure and pump out $5 \mathrm{~N}_{2}$ exposure pump out purging steps were applied. Due to the low vapor pressure of TTIP it was exposed multiple times at 0.5 Torr separated by 360 s pump out during the TTIP exposure step to ensure enough reactant for the entire surface area to be coated. The needed amount of reactant can be estimated by using simple calculations based on the ideal gas law. The metal precursor partial pressure was varied based on the particle load, thus the surface area to be coated. The estimation for the specific surface area of acetaminophen was $1 \mathrm{~m}^{2} / \mathrm{g}$.

\subsection{Thermal analysis of the particles}

The thermal stability of acetaminophen and ALD coated acetaminophen was studied by thermogravimetric analysis (TGA) using a Netzsch TG 209 F1 instrument under nitrogen atmosphere. The powder sample with an initial mass of 10 to $12 \mathrm{mg}$ was placed in an alumina crucible and a thermograph was recorded within a temperature range of $26{ }^{\circ} \mathrm{C}(299 \mathrm{~K})$ to $1000{ }^{\circ} \mathrm{C}$ $(1273 \mathrm{~K})$ with the heating rate of $10 \mathrm{Kmin}^{-1}$. A TGA measurement was also used to estimate the composition of ALD oxide material in coated acetaminophen. Estimation for the composition was performed at around $390{ }^{\circ} \mathrm{C}$ where the uncoated acetaminophen sample showed a complete mass 
loss. The residual mass of ALD coated acetaminophen at $390{ }^{\circ} \mathrm{C}$ was considered to be ALD oxide. This information was used to estimate the composition of ALD oxide material in coated acetaminophen.

Differential scanning calorimetry (DSC) Netzsch DSC 204 F1 was used to investigate the change in enthalpy within the temperature range of $25^{\circ} \mathrm{C}$ to $180{ }^{\circ} \mathrm{C}$ during the heating-cooling cycles. Two heating-cooling cycles were performed for each sample. Samples of around 10 to $12 \mathrm{mg}$ were heated and cooled in an aluminum pan, which was first sealed with an aluminum lid prior to piercing the lid to avoid the pan deforming and losing proper physical contact between the pan bottom and the instrument thermoelement. The heating and cooling rate used was $10 \mathrm{~K} \mathrm{~min}^{-1}$ in a dynamic inert $\mathrm{N}_{2}$ atmosphere with flow rates of $20 \mathrm{ml} \mathrm{min}^{-1}$ for purging and $70 \mathrm{ml} \mathrm{min}^{-1}$ for protective gas flow, respectively. The structure and the structural changes in acetaminophen and ALD coated acetaminophen prior to and after DSC analysis were studied with attenuated total reflectance Fourier transmittance infrared (ATR-FTIR) spectroscopy using a Nicolet 4700 FTIR spectrometer with a Smart Orbit ATR accessory with a diamond crystal internal reflection element.

\subsection{X-ray powder diffraction}

X-Ray powder diffraction (XRPD) analysis was used to confirm the polymorphic form of the acetaminophen and ALD coated acetaminophen samples. XRPD spectra of powder samples were collected by using a Bruker D2 Phaser X-Ray diffraction desktop system with a CuK $\alpha$ anode $(\lambda=$ 1.54184) at room temperature. The powder sample was loaded on a sample holder within the cavities at the center part of the holder and pressed gently on the holder to form a packed round shaped powder bed sample. 


\subsection{Surface characterization of the particles}

Untreated acetaminophen and ALD coated acetaminophen surface morphology, particle size and conformality of ALD coating were analyzed by using a scanning electron microscope with energy dispersive X-ray spectroscopy (SEM-EDS) (Hitachi S4800). The particle cross-section samples were prepared with a focused ion bean scanning electron microscope (FIB-SEM) (FEI Quanta 3D 200i). The samples were coated with Au-Pd alloy and carbon prior to loading them into the FIBSEM to protect the interface against ion beam damage. The protection was completed with an ion beam deposited Pt layer just before the ion beam cutting. EDS elemental maps were measured across the cross-section surfaces with an Oxford INCA 350 EDS connected with the FEI Quanta microscope. Beam energies were $5 \mathrm{keV}$ for the $\mathrm{Al}_{2} \mathrm{O}_{3}$-coated acetaminophen sample and $10 \mathrm{keV}$ for the $\mathrm{TiO}_{2}$-coated acetaminophen sample.

\subsection{Drug stability and release profile}

The acetaminophen degradation products and the drug release profile were determined by high performance liquid chromatography (HPLC, Agilent 1260, Agilent Technologies, USA) using a column Phenomenex Gemini (Nx, $\left.3 \mu \mathrm{m}, \mathrm{C}_{18} 110 \AA\right)$. The mobile phase used for the detection of acetaminophen and possible degradation products used was water at $\mathrm{pH} 3$ and methanol (70:30, $\mathrm{v} / \mathrm{v}$ ) with a flow rate of $1 \mathrm{ml} \mathrm{min}{ }^{-1}$ and $\mathrm{UV}$-detection of products set at a wavelength of $230 \mathrm{~nm}$ at $25^{\circ} \mathrm{C}$. In order to investigate the drug release, $1500-1000 \mu \mathrm{g}$ of acetaminophen and ALD coated acetaminophen were dispersed in $100 \mathrm{ml}$ of phosphate buffered saline (PBS) pH 6.8 and buffer $\mathrm{pH}$ 1.2 , and kept under stirring at $300 \mathrm{rpm}$ while keeping the temperature at $37^{\circ} \mathrm{C}$. Then, $200 \mu \mathrm{L}$ of the PBS at $\mathrm{pH} 6.8$ and buffer at $\mathrm{pH} 1.2$ were withdrawn at pre-determined time points $(2,5,10$, $15,20,30,60,90,120,180,240,360 \mathrm{~min}$ and $24 \mathrm{~h}$ ) for HPLC analyses. The volume of the release 
medium was retained constant by replacing $200 \mu 1$ of the fresh pre-warmed release medium after each sampling. The samples were then centrifuged at $21,382 \mathrm{~g}$ for $3 \mathrm{~min}$ and the released amount of acetaminophen was measured in the supernatant by the HPLC method described above. All experiments were performed at least in triplicate.

\subsection{Cell culture and viability assays}

The in vitro studies with the ALD powders were carried out on the human epithelial colorectal adenocarcinoma Caco-2 cell line (from American Type Culture Collection). The cells were cultured in $75 \mathrm{~cm}^{2}$ culture flasks (Corning Inc. Life Sciences) using Dulbecco's modified Eagle's medium (DMEM, HyClone). The medium was supplemented with 10\% heat inactivated fetal bovine serum (HIFBS, Gibco, Invitrogen), 1\% sodium pyruvate (HyClone), 1\% nonessential aminoacids, $1 \%$ L-glutamine, penicillin (100 IU/ml), and streptomycin $(100 \mathrm{mg} / \mathrm{ml})$ (all from EuroCloneS.p.A). The cultures were maintained in a BB 16 model (Heraeus Instruments GmbH) gas incubator at $37{ }^{\circ} \mathrm{C}$ in an atmosphere of $5 \% \mathrm{CO}_{2}$ and $95 \%$ relative humidity. The growth medium was changed every other day until the time of use. Caco-2 cells from passage numbers $35-40$ were used in all the experiments.

Prior to each test, the cells were harvested using $0.25 \%(\mathrm{v} / \mathrm{v})$ trypsin-ethylenediamine tetraacetic acid- phosphate buffered saline (EDTA-PBS) and seeded at the desired density. For the toxicity assessment, $100 \mu 1$ of a $2 \times 10^{5}$ cells ml $^{-1}$ solution in DMEM were seeded in 96-well plates (PerkinElmer Inc.) and allowed to attach overnight. The medium was then aspirated and the wells were washed once with $100 \mu 1$ of Hank's Balanced Salt Solution (HBSS). Then, $100 \mu 1$ of a solution prepared with ALD coated acetaminophen powders in HBSS with concentrations of 200, 100,50 and $15 \mu \mathrm{g} \mathrm{ml}^{-1}$, HBSS as negative control and Triton X-100 as a positive control were 
added to the wells. After $3 \mathrm{~h}, 6 \mathrm{~h}$ and $24 \mathrm{~h}$ of incubation for $\mathrm{TiO}_{2}\left(\mathrm{TiCl}_{4}\right)$ and $\mathrm{ZnO}$, and $24 \mathrm{~h}$ of incubation for $\mathrm{Al}_{2} \mathrm{O}_{3}$ and $\mathrm{TiO}_{2}$ (TTIP), the wells were washed once with HBSS and $50 \mu \mathrm{l}$ of fresh HBSS was then added to the wells along with $50 \mu 1$ of the CellTiter-Glo ${ }^{\circledR}$ reagent assay (Promega Corporation), according to the manufacturer's instructions. In this assay the number of viable cells in culture is quantified based on the amount of adenosine triphosphate (ATP) produced by metabolically active cells. Thus, the amount of ATP produced is directly proportional to the number of living cells presented in the culture. The plate was then measured for luminescence using a Varioskan Flash fluorometer (Thermo Fisher Scientific). The luminescence of the sample wells was then compared with their time-paired controls. The results are the averages of three independent experiments and error bars represent mean \pm standard deviation (SD).

\subsection{Reactive oxygen species (ROS) determination}

The experiments were performed as described elsewhere (Bimbo et al., 2011). In brief, $100 \mu \mathrm{L}$ of a $2 \times 10^{5}$ cells $\mathrm{ml}^{-1}$ solution in DMEM were seeded in 96-well plates and allowed to attach overnight. The medium was then aspirated, and afterwards, $100 \mu 1$ of $10 \mu \mathrm{M} 2^{\prime}, 7^{\prime}-$ dichlorofluorescin diacetate (DCF-DA, Sigma Aldrich) solution was added to the wells and allowed to incubate for $1 \mathrm{~h}$ at $37^{\circ} \mathrm{C}$. The solution was subsequently removed and the wells were washed with $100 \mu$ of fresh HBSS. Then, the $\mathrm{TiO}_{2}\left(\mathrm{TiCl}_{4}\right)$ and $\mathrm{ZnO}$ ALD powder suspensions of concentrations of $200,100,50$, and $15 \mu \mathrm{g} \mathrm{ml}^{-1}$ were added to the wells, with hydrogen peroxide treated cells $\left(\mathrm{H}_{2} \mathrm{O}_{2}, 0.09 \%\right)$ used as a positive control, and HBSS treated as a negative control. After incubating for $3 \mathrm{~h}$ and $6 \mathrm{~h}$, the plate wells were washed with fresh HBSS and DCF fluorescence was measured in a Varioskan Flash (Thermo Fisher Scientific) with excitation and 
emission wavelengths of 498 and $522 \mathrm{~nm}$, respectively. All the assays were conducted at least in triplicate and error bars represent \pm SD.

\subsection{Tumor necrosis factor alpha (TNF- $\alpha)$ assay}

The assessment of inflammatory response by measuring TNF- $\alpha$ production was also carried out in Caco-2 cells incubated with the ALD powder. An enzyme-linked immunosorbent assay (ELISA) was conducted using a commercially available kit (Human TNF- $\alpha$ ELISA kit, Thermo

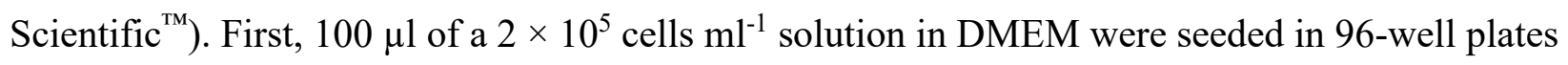
and allowed to attach overnight. The medium was then aspirated, and afterwards the wells were washed with $100 \mu 1$ of fresh HBSS. Then, the ZnO ALD powder suspensions of concentrations of 200, 100, 50, and $15 \mu \mathrm{g} \mathrm{ml}^{-1}$ were added to the wells, as well as HBSS as a negative control. After incubating for $3 \mathrm{~h}, 6 \mathrm{~h}$ and $24 \mathrm{~h}$, the supernatants were collected in Eppendorfs and stored immediately at $-80{ }^{\circ} \mathrm{C}$ for later analysis. Serial dilutions of human TNF- $\alpha$ were then prepared and added to the wells of a 96-well plate pre-coated with immobilized antibodies. The thawed supernatants were subsequently centrifuged at $13,362 \mathrm{~g}$ for $30 \mathrm{~min}$ and the top fraction $(50 \mu \mathrm{l})$ was collected and pipetted into each well of the same 96-well plate and incubated for $1 \mathrm{~h}$ at room temperature. The plate was then washed three times with wash buffer and $100 \mu 1$ of Biotinylated Antibody Reagent was added to the wells and subsequently incubated for $1 \mathrm{~h}$. The plate was further washed three times with wash buffer and $100 \mu$ of Streptavidin Horse Radish Peroxidase (HRP) Reagent were added to the wells and incubated for $30 \mathrm{~min}$. Then, the plate was again washed three times with wash buffer and $100 \mu 1$ of 3,3',5,5'-Tetramethylbenzidine (TMB) Substrate was added to each well and incubated for another $30 \mathrm{~min}$. After the last incubation time, $100 \mu 1$ of Stop Solution was added to the wells and the absorbance was measured at $450 \mathrm{~nm}$ and $550 \mathrm{~nm}$ in a 
Varioskan Flash (Thermo Fisher Scientific). The amount of TNF- $\alpha$ present in each sample was determined by subtracting the absorbance values at 550 from the absorbance values at $450 \mathrm{~nm}$ to correct from optical imperfection on the plate, and then calculating the total amount from the standard curve of known amounts of human TNF- $\alpha$.

\subsection{Statistical analysis}

Results from the several tests are expressed as mean \pm SD from of at least three independent experiments. A one-way analysis of variance (ANOVA), followed by a Dunnett's multiple comparison test was used to analyze the cell viability, ROS levels and TNF- $\alpha$ induction. The level of significance was set at a probability of $\mathrm{p}<0.05$ for $*$, $\mathrm{p}<0.01$ for $* *$, and $\mathrm{p}<0.001$ for $* * *$. The analysis was carried out using GraphPad Prism v. 6.07 (GraphPad Software).

\section{RESULTS AND DISCUSSION}

\subsection{DSC}

In order to confirm the crystalline state, powder X-ray diffractograms (Figure S1) were performed on pure acetaminophen and the ALD coated samples. The results (Figure S1) indicate that the crystal structure in all samples is monoclinic polymorph I. The change in peak intensities is attributed to the preferred orientation (Shi and Sun, 2011). Temperature and enthalpy of fusion of acetaminophen and ALD coated acetaminophen samples are summarized in Table S1. The DSC scans from a thermal cycle of acetaminophen and $\mathrm{ALD} \mathrm{Al}_{2} \mathrm{O}_{3}$ and $\mathrm{TiO}_{2}\left(\mathrm{TiCl}_{4}\right)$ coated acetaminophen powders are shown in Figure 2a. Thermal cycling of acetaminophen has been extensively reported in the literature, providing support for this analysis (Sacchetti, 2001; Rossi et al., 2003; Ledru et al., 2007; Trasi and Taylor, 2012; Klímová and Leitner, 2012). The thermograph 
(a) in Figure 2a represents typical behavior of the first heating and melting of the monoclinic form (polymorphic form I) of acetaminophen at $169{ }^{\circ} \mathrm{C}$ (onset value) with enthalpy of fusion of 168.3 $\mathrm{J} / \mathrm{g}^{-1}$. Both 20 and $50 \mathrm{ALD} \mathrm{Al}_{2} \mathrm{O}_{3}$ cycles coated acetaminophen powders melted at the same temperature as acetaminophen and with enthalpy of fusion of 167.4 and $162.5 \mathrm{~J} \mathrm{~g}^{-1}$ respectively. Clearly different behavior can be seen in the $50 \mathrm{ALD} \mathrm{TiO} 2\left(\mathrm{TiCl}_{4}\right)$ cycles coated acetaminophen DSC scan in Figure 2a (thermograph d). First, an additional endothermic reaction can be seen at $159^{\circ} \mathrm{C}$ with enthalpy of fusion of $2.761 \mathrm{~J} \mathrm{~g}^{-1}$ followed by the melting of form I at $172.7^{\circ} \mathrm{C}$ with enthalpy of fusion of $128.9 \mathrm{~J} \mathrm{~g}^{-1}$. This enthalpy of fusion of form I is clearly lower than for any other samples in this study. It is evident that a perceptible part of the acetaminophen surface has transformed from form I to a different form or state. The system formed due to the ALD $\mathrm{TiO}_{2}$ $\left(\mathrm{TiCl}_{4}\right)$ layer has nearly the same melting temperature as the orthorhombic form (polymorphic form II) of acetaminophen. Considering the thermal cycle that acetaminophen undergoes during ALD coating process it is unlikely that the existing form I would transform into form II. According to literature this could happen if the form I is first melted, then cooled near room temperature and heated again to over $70{ }^{\circ} \mathrm{C}$. A more likely explanation is that the $\mathrm{TiO}_{2}\left(\mathrm{TiCl}_{4}\right)$ forms a binary system together with the surface layer of acetaminophen, where the coating acts as an impurity depressing the melting point of acetaminophen. Furthermore, it is known that binary systems of acetaminophen and excipients decrease the initial melting temperature of acetaminophen and reduce a degree of crystallinity of acetaminophen products (Rossi et al., 2003; Klímová and Leitner, 2012; Kayaly et al. 2014). Since the form I of acetaminophen remains as the main component in the ALD $\mathrm{TiO}_{2}\left(\mathrm{TiCl}_{4}\right)$ coated acetaminophen the formed system is not a simple eutectic system suggesting that only a surface reaction has taken place. Furthermore, it is proposed that by-products from the process, such as $\mathrm{HCl}$, may transform some parts of the surface into 
amorphous via melting point depression. It is possible that the endothermic reaction seen at 159 ${ }^{\circ} \mathrm{C}$ for the $\mathrm{ALD} \mathrm{TiO}_{2}\left(\mathrm{TiCl}_{4}\right)$ sample is due to acetaminophen crystallization from amorphous to form II during the DSC measurement. This mechanism would mean that $\mathrm{TiO}_{2}$ coating prolongs higher energy amorphous acetaminophen crystallization. The thermograph of 20 ALD cycles $\mathrm{Al}_{2} \mathrm{O}_{3}$ and 50 cycles $\mathrm{TiO}_{2}\left(\mathrm{TiCl}_{4}\right)$ nanolaminate on acetaminophen in Figure 2a (thermograph e) shows that $\mathrm{Al}_{2} \mathrm{O}_{3}$ coating protects acetaminophen from the formation of a mixed system between acetaminophen and $\mathrm{TiO}_{2}\left(\mathrm{TiCl}_{4}\right)$.

As a comparison, another $\mathrm{TiO}_{2}$ chemistry using TTIP and $\mathrm{H}_{2} \mathrm{O}$ was studied (marked as $\mathrm{TiO}_{2}$ (TTIP)). The TTIP and $\mathrm{H}_{2} \mathrm{O}$ chemistry is well studied for $\mathrm{ALD} \mathrm{TiO}_{2}$ and can be used to avoid the formation of $\mathrm{HCl}$ by-products. A thermograph of an acetaminophen sample coated with $\mathrm{TiO}_{2}$ (TTIP) in Figure 2b (thermograph d) does not show the endothermic reaction at $159{ }^{\circ} \mathrm{C}$ observed in $\mathrm{TiO}_{2}\left(\mathrm{TiCl}_{4}\right)$ sample indicating that the formation of a binary system detected by DSC can be avoided by using TTIP as the precursor. $\mathrm{TiO}_{2}$ (TTIP) grown sample melts at $168.7{ }^{\circ} \mathrm{C}$ with enthalpy of fusion of $195.7 \mathrm{~J} \mathrm{~g}^{-1}$. The thermograph of the $\mathrm{ZnO}$ coated acetaminophen sample in Figure 2b (thermograph c) reveals similar behavior to uncoated acetaminophen in Figure $\mathbf{2 b}$ (thermograph a) and $\mathrm{TiO}_{2}$ (TTIP) coated sample, where it melts at $169.2{ }^{\circ} \mathrm{C}$ with the enthalpy of fusion of $181.9 \mathrm{~J} \mathrm{~g}^{-1}$. A decrease in melting point due to the ALD coating substance present in acetaminophen can be observed from the thermographs and data of the 50 cycles $\mathrm{Al}_{2} \mathrm{O}_{3}, 50$ cycles $\mathrm{TiO}_{2}\left(\mathrm{TiCl}_{4}\right)$ and $\mathrm{Al}_{2} \mathrm{O}_{3}$ and $\mathrm{TiO}_{2}\left(\mathrm{TiCl}_{4}\right)$ nanolaminate samples shown in Figures $2 \mathbf{a}$ and $2 \mathbf{b}$ and in Table S1. The thermograph of 50 cycles $\mathrm{TiO}_{2}$ (TTIP) in Figure 2b (thermograph d) has the same melting temperature as uncoated acetaminophen where a slight peak broadening towards lower temperature is observable. The thermograph of $\mathrm{ZnO}$ coated acetaminophen in Figure $\mathbf{2 b}$ (thermograph c) has the same melting temperature with uncoated acetaminophen and possess no 
peak broadening. In pure substances the melting curve give a symmetric peak while in impure substances the melting temperature decreases and the curve appears broader and asymmetric. The theory of thermodynamics of two-component systems allows the determination of the purity of eutectic mixtures (Höhne et al., 1996).

Figures $2 \mathbf{c}$ and $\mathbf{2 d}$ show DSC thermographs after reheating the amorphous samples from the first heating-cooling DSC cycle. The temperature with enthalpy of crystallization and fusion are summarized in Table S2. A thermograph (a) In Figure 2c depicts a typical thermograph of acetaminophen, where it crystallizes into the polymorph III at $79.4{ }^{\circ} \mathrm{C}$ under thermal cycling, then crystallizes to polymorph II before melting at $156.9^{\circ} \mathrm{C}$ (peat at $163.6^{\circ} \mathrm{C}$ ) with enthalpy of fusion of $167.7 \mathrm{~J} \mathrm{~g}^{-1}$. Crystallization into polymorph II is immediate after the crystallization of polymorph III since no exothermic reaction can be seen in the thermograph. In the presence of ALD coating material the crystallization into the polymorph III is shifted to higher temperatures, which appears to increase with the coating thickness, i.e., amount of ALD material in the mixture. This can be seen as an increased crystallization temperature for the 50 cycles $\mathrm{Al}_{2} \mathrm{O}_{3}$ coated sample (thermograph $\mathrm{c}$ in Figure 2c) compared to the 20 cycles $\mathrm{Al}_{2} \mathrm{O}_{3}$ coated sample ( thermograph $\mathrm{b}$ in Figure 2c). Crystallization into polymorph II is visible and measurable for the samples with $\mathrm{Al}_{2} \mathrm{O}_{3}$ and $\mathrm{TiO}_{2}\left(\mathrm{TiCl}_{4}\right)$, which is shown as an exothermic transition at near $140{ }^{\circ} \mathrm{C}$ in thermographs (be) in Figure 2c. Furthermore, the thermographs of both 50 cycles $\mathrm{Al}_{2} \mathrm{O}_{3}$ and $\mathrm{TiO}_{2}\left(\mathrm{TiCl}_{4}\right)$ clearly show the melting of the polymorph III at 137.5 and $142.1{ }^{\circ} \mathrm{C}$, respectively. This is followed by the exothermic transition (crystallization into the polymorph II) before melting takes place at $161^{\circ} \mathrm{C}$ and $160.8{ }^{\circ} \mathrm{C}$, respectively. Similar behavior has been observed with mixed systems of acetaminophen and polymers, where the amount of polymer in the mixture has been $10-15 \mathrm{w}-\%$ (Trasi and Taylor, 2012). 
Figure 2d presents a comparison between samples with $50 \mathrm{ALD}$ cycles of $\mathrm{Al}_{2} \mathrm{O}_{3}, \mathrm{TiO}_{2}$ and $\mathrm{ZnO}$. The thermograph of the samples having $\mathrm{ZnO}$ (thermograph e in Figure 2d) and $\mathrm{TiO}_{2}$ (TTIP) (thermograph d in Figure 2d) have slightly different behavior compared to samples with $\mathrm{Al}_{2} \mathrm{O}_{3}$ and $\mathrm{TiO}_{2}\left(\mathrm{TiCl}_{4}\right)$. The thermograph of the sample with $\mathrm{ZnO}$ shows exothermic transition at 79.4 ${ }^{\circ} \mathrm{C}$ attributed to the crystallization into polymorph III followed by the crystallization into polymorph II (seen as a small alteration in the thermograph at $135^{\circ} \mathrm{C}$ ) before melting of polymorph II at $156.8{ }^{\circ} \mathrm{C}$ with enthalpy of fusion of $176.1 \mathrm{~J} \mathrm{~g}^{-1}$. The thermograph of the sample containing $\mathrm{TiO}_{2}$ (TTIP) shows the exothermic transition at $81.6^{\circ} \mathrm{C}$ attributed to the crystallization into polymorph III followed by crystallization into polymorph II at $136.7^{\circ} \mathrm{C}$ before melting of polymorph II at $156.7^{\circ} \mathrm{C}$ with enthalpy of fusion of $171.4 \mathrm{~J} \mathrm{~g}^{-1}$. 

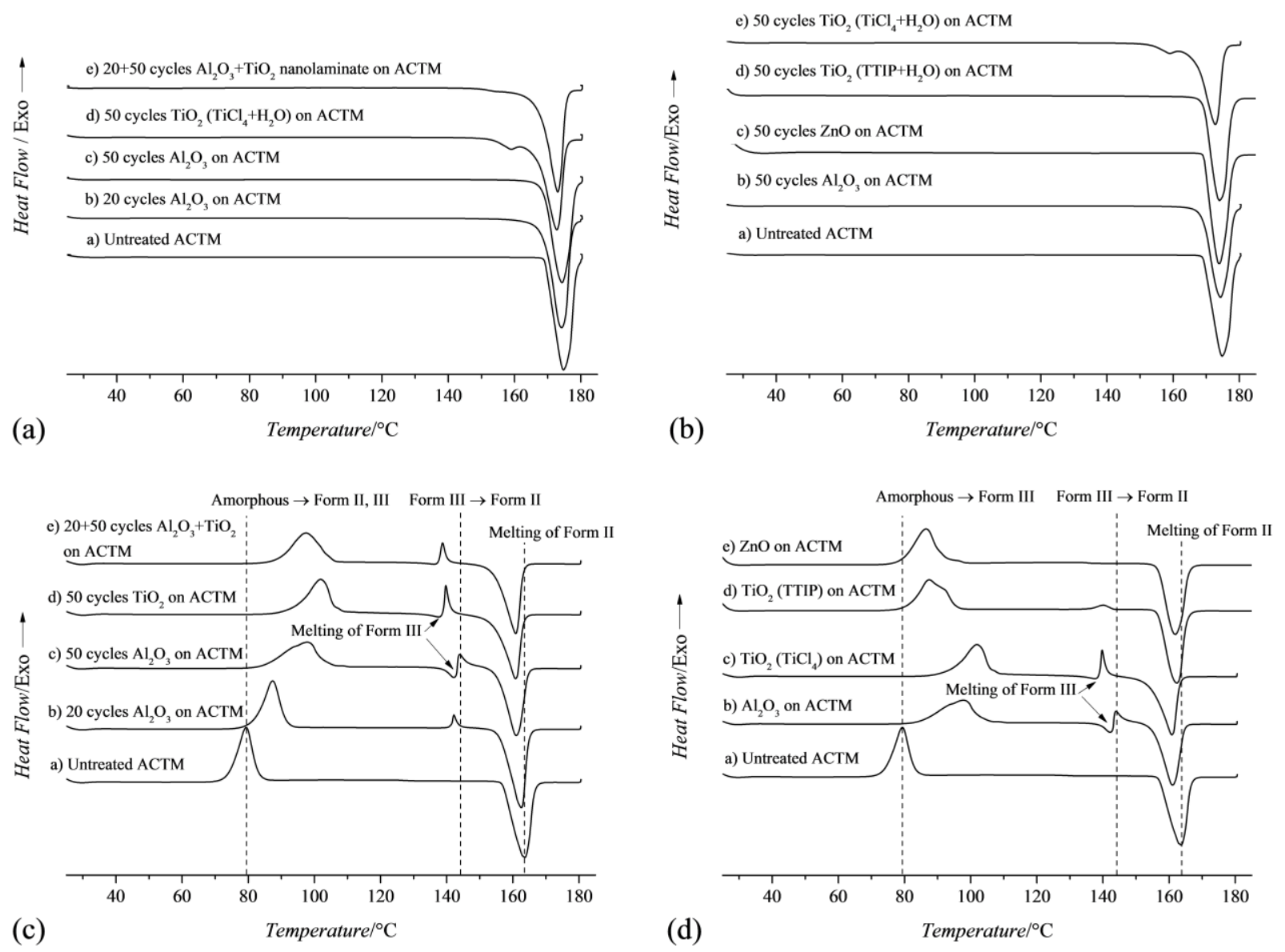

Figure 2. DSC thermographs during the first heating cycle of pure acetaminophen and ALD oxide coated acetaminophen ( $\mathrm{a}$ and $\mathrm{b}$ ) and during the second heating cycle of pure acetaminophen and ALD oxide coated acetaminophen (c and d) with the heating rate of $10 \mathrm{~K} \mathrm{~min}^{-1}$ in a dynamic inert $\mathrm{N}_{2}$ atmosphere. The scans have been offset vertically for clarity.

\subsection{Thermogravimetric analysis (TGA)}

Thermogravimetric curves and differential thermogravimetric (DTG) curves, presenting the rate of mass loss at certain temperature, of acetaminophen and ALD oxide coated acetaminophen obtained during heating in $\mathrm{N}_{2}$ are shown in Figure 3. The mass loss and mass loss rate during the thermogravimetric measurement of acetaminophen and ALD coated acetaminophen samples at different temperatures are also summarized in Table S3. All the samples are stable up to around 
$270{ }^{\circ} \mathrm{C}$. This onset temperature at which the mass loss starts to increase rapidly has been extrapolated from the thermographs. All the coated samples regardless of the coating material or thickness have slightly lower onset temperature compared to untreated acetaminophen, being near $265^{\circ} \mathrm{C}$. It seems that at this thickness range ALD coating has a negligible effect on the thermal stability of acetaminophen. A closer look at the thermogravimetric curves (Figure 3 insets) reveals a difference in mass loss between the samples below the onset temperature of $265^{\circ} \mathrm{C}$. The mass loss at $150{ }^{\circ} \mathrm{C}$ for bare acetaminophen is approximately $0.03 \%$, indicating that acetaminophen itself has very low content of volatile species, such as absorbed water. All the ALD coated acetaminophen samples (besides $\mathrm{ZnO}$ ) have higher mass loss at $150{ }^{\circ} \mathrm{C}$ than untreated acetaminophen attributed to desorption of volatile species from the coating. Negative residual mass of $\mathrm{ZnO}$ at $150^{\circ} \mathrm{C}$ is due to an error in thermogravimetric data based on the buoyancy effect, caused by the decrease of the gas density when heated. Considering the initial sample mass to the point where the mass is the highest due to the buoyancy effect (at $55^{\circ} \mathrm{C}$ for the $\mathrm{ZnO}$ sample), the mass loss for the $\mathrm{ZnO}$ coated sample at $150{ }^{\circ} \mathrm{C}$ is $0.14 \%$. By applying the same consideration to the rest of the samples the mass losses for the untreated acetaminophen, 20 cycles $\mathrm{Al}_{2} \mathrm{O}_{3}, 50$ cycles $\mathrm{Al}_{2} \mathrm{O}_{3}$, 50 cycles $\mathrm{TiO}_{2}\left(\mathrm{TiCl}_{4}\right), 20+50$ cycles $\mathrm{Al}_{2} \mathrm{O}_{3}$ and $\mathrm{TiO}_{2}\left(\mathrm{TiCl}_{4}\right), \mathrm{TiO}_{2}(\mathrm{TTIP})$ are $0.19 \%, 0.26 \%$, $0.30 \%, 0.59 \%, 0.44 \%$ and $0.24 \%$, respectively. This assumes that the initial sample weight to the highest point of the gained mass due the buoyancy effect does not change the order of the mass losses between the samples. The $\mathrm{ZnO}$ coated sample has the lowest mass loss at $150{ }^{\circ} \mathrm{C}$ indicating least volatile species in the sample. The highest mass loss of $\mathrm{TiO}_{2}\left(\mathrm{TiCl}_{4}\right)$ coated acetaminophen at $150{ }^{\circ} \mathrm{C}$ may be due to desorption of a binary system component detected also in the DSC measurement (in addition to desorption of impurities from the coating). This eutectic system has a lower melting point and may start to decompose the $\mathrm{TiO}_{2}$-acetaminophen complex around the 
eutectic onset temperature of $153.7^{\circ} \mathrm{C}$ found in DSC. This is clearly observable from the thermogravimetric curve of $\mathrm{TiO}_{2}\left(\mathrm{TiCl}_{4}\right)$ deposited acetaminophen sample as a sudden decrease in residual mass (Figures 3a and $\mathbf{3 b}$ insets), and as a sudden increase in the mass loss rate at around $152{ }^{\circ} \mathrm{C}$ (Figures 3c and 3d insets). The lower mass loss of the nanolaminate sample having 20 cycles $\mathrm{Al}_{2} \mathrm{O}_{3}$ underneath the $\mathrm{TiO}_{2}\left(\mathrm{TiCl}_{4}\right)$ indicates the protecting characteristics of 20 cycles $\mathrm{Al}_{2} \mathrm{O}_{3}$ from the effect of $\mathrm{TiO}_{2}\left(\mathrm{TiCl}_{4}\right)$. As found in $\mathrm{DSC}$ the formation of a binary system between acetaminophen and $\mathrm{TiO}_{2}\left(\mathrm{TiCl}_{4}\right)$ is not completely blocked with 20 cycles $\mathrm{Al}_{2} \mathrm{O}_{3}$. This is also observable in the DTG curve for the nanolaminate sample, where the increase in the mass loss rate is shown around $152{ }^{\circ} \mathrm{C}$. Similar increase in mass loss rate is not observable for the 20 cycles $\mathrm{Al}_{2} \mathrm{O}_{3}$ sample. $\mathrm{TiO}_{2}(\mathrm{TTIP})$ has lower mass loss at $150{ }^{\circ} \mathrm{C}$ than $\mathrm{TiO}_{2}\left(\mathrm{TiCl}_{4}\right)$ suggesting a lower amount of volatile species in the sample. The mass loss increases for all of the samples at the melting temperature of acetaminophen (the onset temperature is $169^{\circ} \mathrm{C}$ and the peak temperature is $175^{\circ} \mathrm{C}$ ) still is less than $1 \%$. At the onset temperature in TGA the mass loss for all of the samples is around 20\%. All the ALD coated samples have a slightly lower decomposition temperature than untreated acetaminophen denoted by the inflection point (the greatest mass loss rate of the sample) in the derivative thermogravimetric curves in Figures 3c and 3d. The inflection point from DTG for the untreated acetaminophen is at $310{ }^{\circ} \mathrm{C}$, while for the ALD coated acetaminophen samples it is around $300{ }^{\circ} \mathrm{C}$. After the inflection point the mass loss rate decreases rapidly for all the samples except the 50 cycles $\mathrm{Al}_{2} \mathrm{O}_{3}$ coated acetaminophen by levelling off close to zero after around $320^{\circ} \mathrm{C}$. The 50 cycles $\mathrm{Al}_{2} \mathrm{O}_{3}$ coated acetaminophen sample continues the mass loss with higher rate compared to the other samples indicating more stable decomposable carbonaceous species in the samples. The mass loss of the acetaminophen sample at $388.5{ }^{\circ} \mathrm{C}$ becomes zero, which has been used as an observation point for further analysis. The mass loss at 
$388.5^{\circ} \mathrm{C}$ for acetaminophen, acetaminophen coated with 20 cycles $\mathrm{Al}_{2} \mathrm{O}_{3}, 50$ cycles $\mathrm{Al}_{2} \mathrm{O}_{3}, 50$ cycles $\mathrm{TiO}_{2}\left(\mathrm{TiCl}_{4}\right)$, nanolaminate of 20 cycles $\mathrm{Al}_{2} \mathrm{O}_{3}$ and 50 cycles $\mathrm{TiO}_{2}\left(\mathrm{TiCl}_{4}\right), 50$ cycles $\mathrm{TiO}_{2}$ (TTIP) and 50 cycles $\mathrm{ZnO}$ are $99.53 \%, 98.48 \%, 93.05 \%, 94.62 \%, 95.38 \%, 95.72 \%$ and $93.62 \%$, respectively. Subtracting the mass loss from the initial sample weight results in the residual masses of $0 \%, 1 \%, 6.44 \%, 4.83 \%, 4.16 \%, 3.87 \%$ and $6.02 \%$, denoting the residual sample masses of 0 , $0.11,0.67,0.53,0.49,0.49$, and $0.83 \mathrm{mg}$, respectively. By assuming that the residual mass of the samples at $388.5^{\circ} \mathrm{C}$ contains mostly ALD oxide material, the ratio of the active pharmaceutical ingredient to the total content of the drug formulation, i.e. drug loading, can be defined. The assumption that the residual mass at $388.5^{\circ} \mathrm{C}$ contains mostly ALD oxide material is reasonable since the DTG values and the mass loss rate of ALD coated samples are smaller or at least the same as the mass loss rate of acetaminophen sample at this temperature. The drug loading estimated based on the residual mass for all of the ALD coated samples is above $90 \%$. 

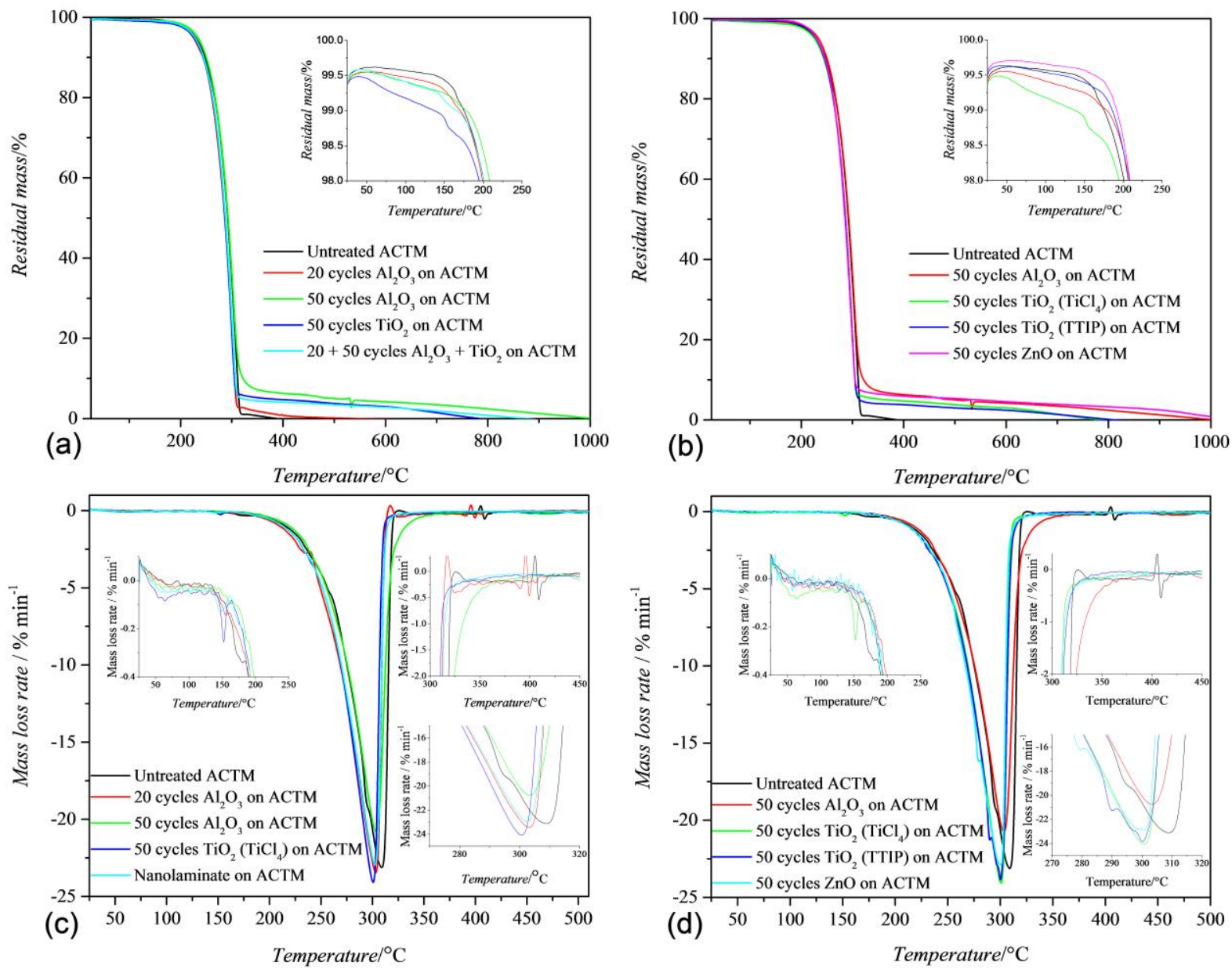

Figure 3. Thermogravimetric curves of acetaminophen and ALD oxide coated acetaminophen obtained during the heating in $\mathrm{N}_{2}$ ( $\mathrm{a}$ and $\mathrm{b}$ ), and differential thermogravimetric (DTG) curves of the same samples, presenting the mass loss rate at certain temperature ( $c$ and $d$ ).

\subsection{ATR-FTIR}

The IR spectra shown in Figure 4 indicate that all the same assignments of the bands to acetaminophen and ALD coated acetaminophen samples can be attributed to the monoclinic form (polymorph I) of acetaminophen. The assignments of the bands associate to the functional groups including the monoclinic band at $806 \mathrm{~cm}^{-1}$, NH bending at $1562 \mathrm{~cm}^{-1}$, aromatic $\mathrm{C}=\mathrm{C}$ stretching at $1608 \mathrm{~cm}^{-1}, \mathrm{C}=\mathrm{O}$ amide stretching at $1651 \mathrm{~cm}^{-1}$, phenolic $\mathrm{OH}$ stretching between $3000-3500 \mathrm{~cm}^{-}$ 1, and NH amide stretching at $3322 \mathrm{~cm}^{-1}$ (Trasi and Taylor, 2012; Kaialy et al., 2014; Qi et al., 
2008; Zimmerman and Baranovic, 2011; Zhao et al., 2014). The IR spectra of ALD coated acetaminophen do not reveal any structural changes in acetaminophen when compared to uncoated acetaminophen. This does not rule out the possibility of chemical reactions between the acetaminophen and nanoscale ALD coating since the penetration depth of ATR-FTIR is typically higher than $0.5 \mu \mathrm{m}$. However, the sensitivity of ATR-FTIR is improved by higher surface area of the particle samples compared to a single planar sample. This benefit can be seen especially from the IR spectra of 50 cycles $\mathrm{TiO}_{2}$ (TTIP) and $\mathrm{ZnO}$ samples between 3000 and $3500 \mathrm{~cm}^{-1}$ (Figure $4 \mathbf{e}$ and $\mathbf{4 f}$ ), where the increase in intensity of $\mathrm{OH}$ stretching vibration attributed to the $\mathrm{OH}$ in ALD oxide coating is observable.

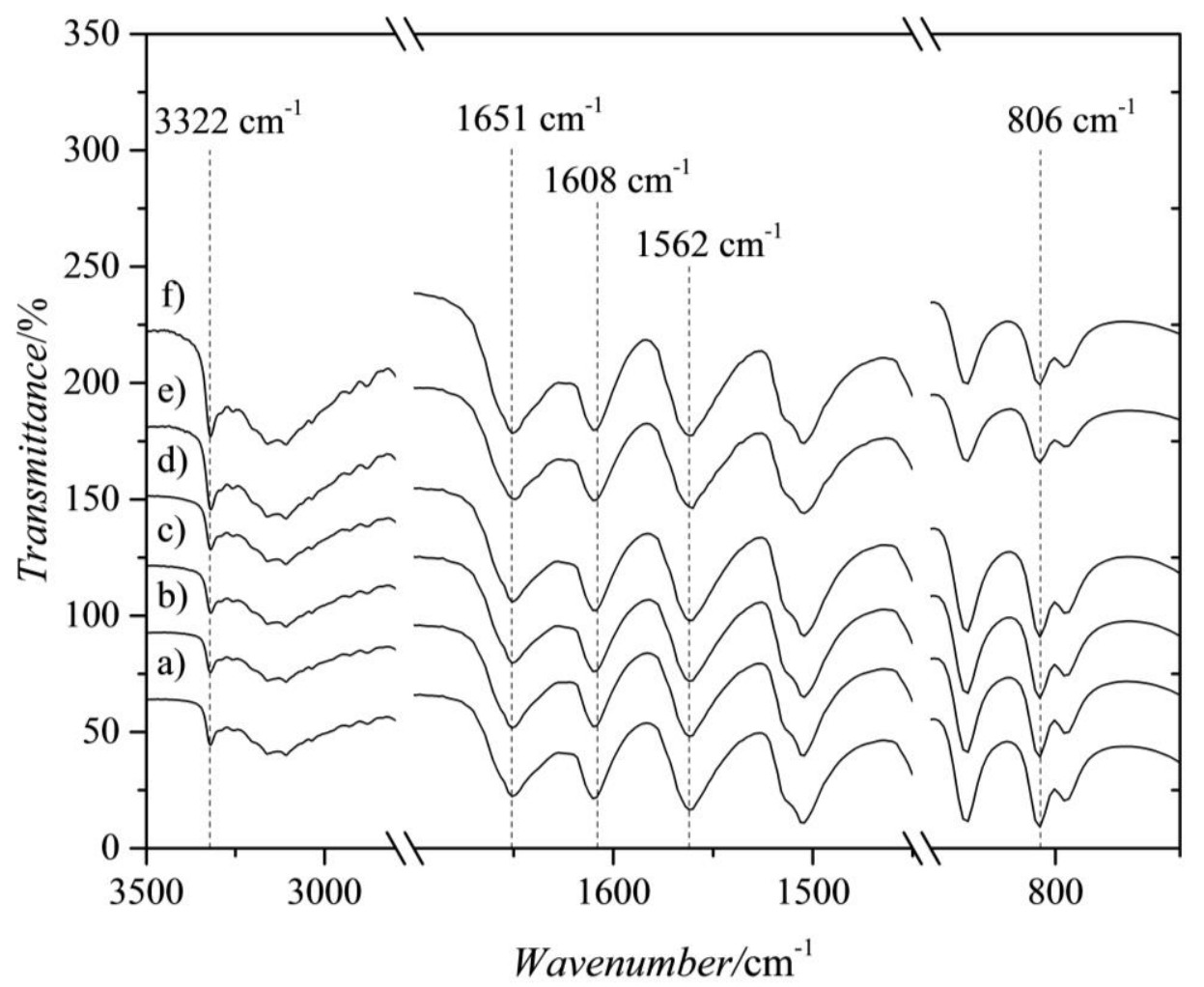

Figure 4. ATR-FTIR spectra of powder samples of a) untreated acetaminophen, b) 50 cycles ALD $\mathrm{Al}_{2} \mathrm{O}_{3}$ on acetaminophen, c) 50 cycles ALD $\mathrm{TiO}_{2}\left(\mathrm{TiCl}_{4}\right)$ on acetaminophen, d) 20 cycles ALD $\mathrm{Al}_{2} \mathrm{O}_{3}+50$ cycles $\mathrm{TiO}_{2}\left(\mathrm{TiCl}_{4}\right)$ on acetaminophen, e) 50 cycles $\mathrm{TiO}_{2}$ (TTIP) on acetaminophen, and f) 50 cycles $\mathrm{ZnO}$ on acetaminophen. 


\subsection{SEM/EDS analysis}

Scanning electron microscopy images of uncoated and ALD coated acetaminophen particles in Figure 5 confirm the irregular shape and size distribution of the particles. Deposition on acetaminophen does not induce any apparent change in particle shape or size distribution or in surface properties, which is revealed in the higher magnification images in Figures $\mathbf{5 b} \mathbf{b}, \mathbf{d}, \mathbf{f}, \mathbf{h}$ and j. To confirm the existence and uniformity of ALD oxide coating on acetaminophen, energy dispersive X-ray spectroscopy (EDS) elemental mapping and point spectrum collection were performed on the ALD coated acetaminophen samples.

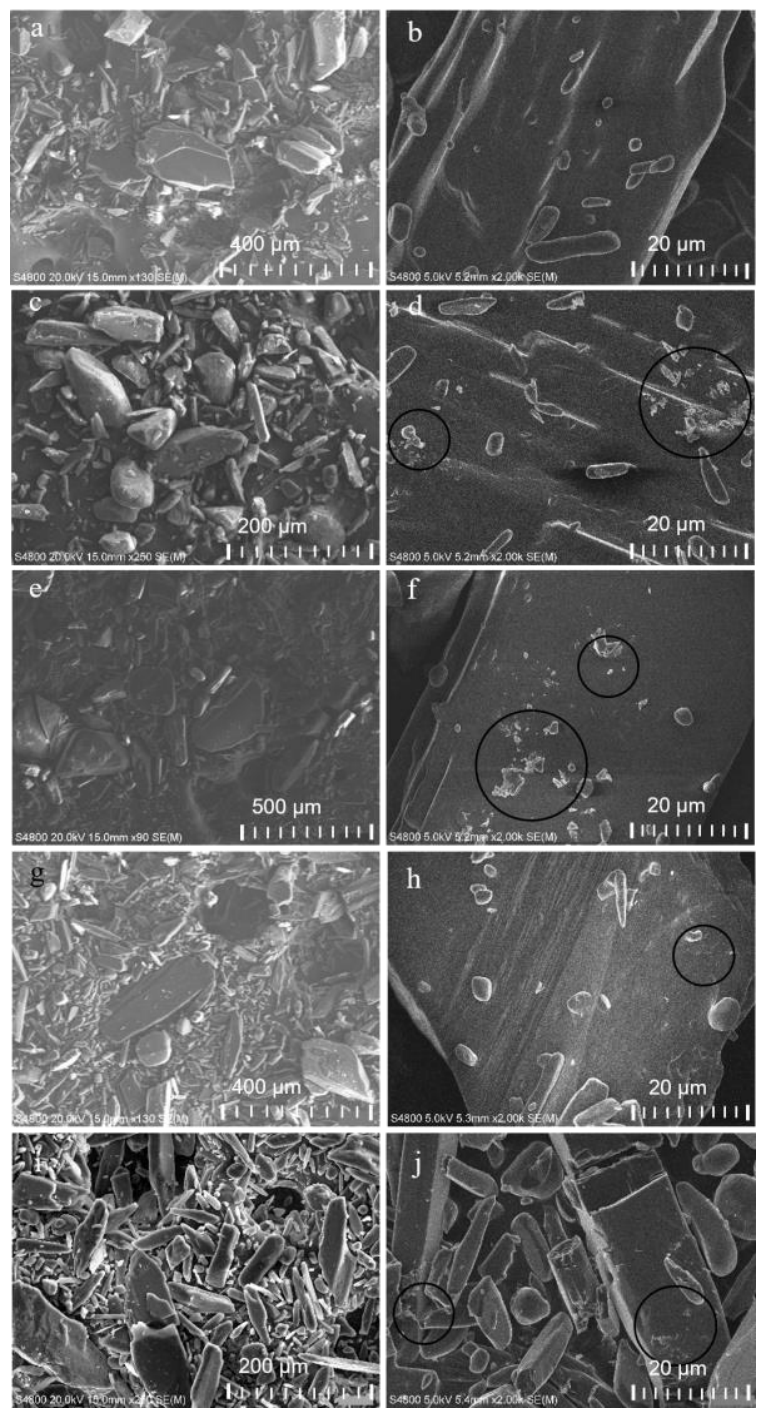

Figure 5. SEM images of $a$ and $b$ ) untreated acetaminophen powder sample, $\mathrm{c}$ and d) 50 cycles ALD $\mathrm{Al}_{2} \mathrm{O}_{3}$ coated acetaminophen sample, e and f) 50 cycles ALD $\mathrm{TiO}_{2}\left(\mathrm{TiCl}_{4}\right)$ coated acetaminophen sample, g and h) 50 cycles $\mathrm{TiO}_{2}$ (TTIP) coated acetaminophen sample, and $\mathrm{i}$ and $\mathrm{j}$ ) 50 cycles $\mathrm{ZnO}$ coated acetaminophen sample. 
The elemental mapping from images shown in Figure 6 confirms the uniform distribution of metal elements (Al, Ti, Zn) on the acetaminophen particle samples, indicating uniform ALD metal oxide deposition over the particles. The presence of ALD oxide coating on individual particles was further demonstrated by the EDS point analysis on the particle surfaces and elemental mapping across the particle cross-section surface. The images in Figure 7 show points where EDS point analysis were done. The EDS point analysis confirmed the existence of the metal element from ALD oxide in each point measured except the point for spectrum 5 in Figure 7c indicating absence of ALD coating. The difference between the areas on the individual particle showed by spectra 5 , 1 and 6 is evident.

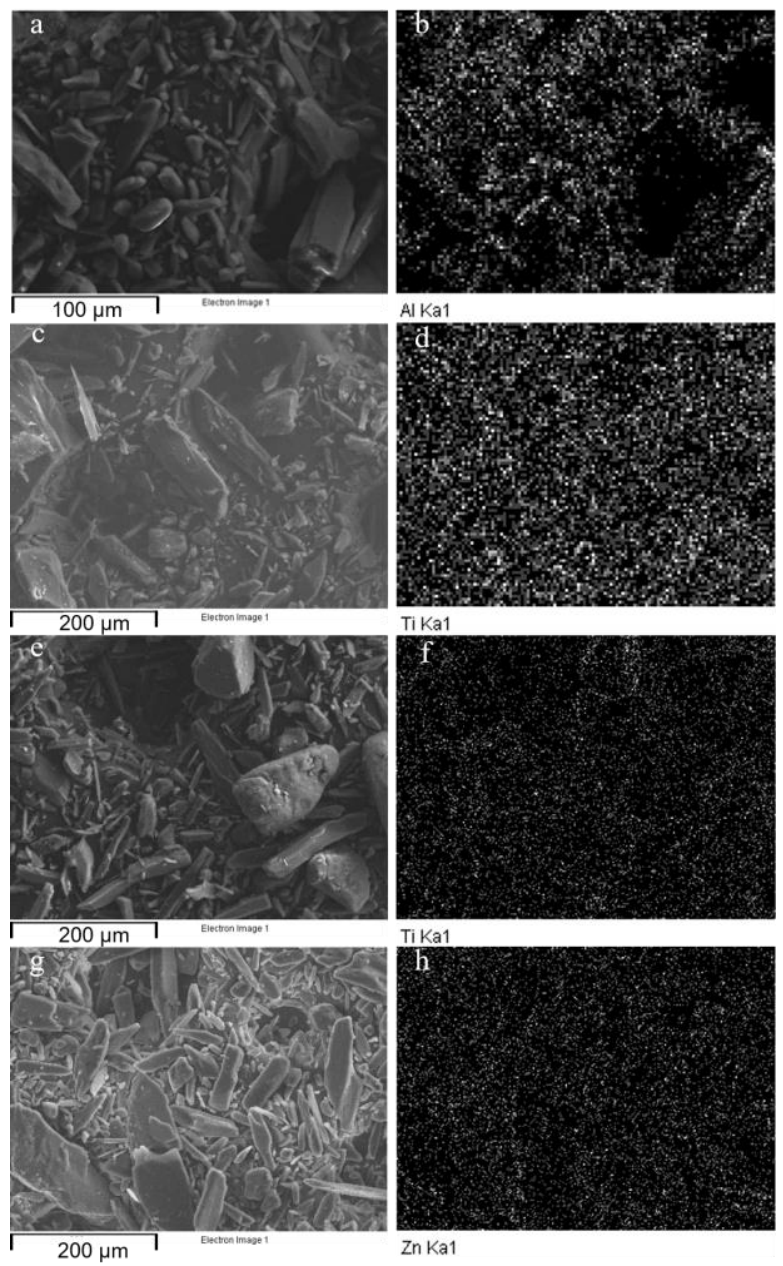

Figure 6. Elemental mapping of a-b) 50 cycles $\mathrm{ALD} \mathrm{Al}_{2} \mathrm{O}_{3}$ coated acetaminophen sample, c-d) 50 cycles ALD $\mathrm{TiO}_{2}\left(\mathrm{TiCl}_{4}\right)$ coated acetaminophen sample, e-f) 50 cycles $\mathrm{TiO}_{2} \quad$ (TTIP) coated acetaminophen sample, and g-h) 50 cycles $\mathrm{ZnO}$ coated acetaminophen sample by SEM with EDS 

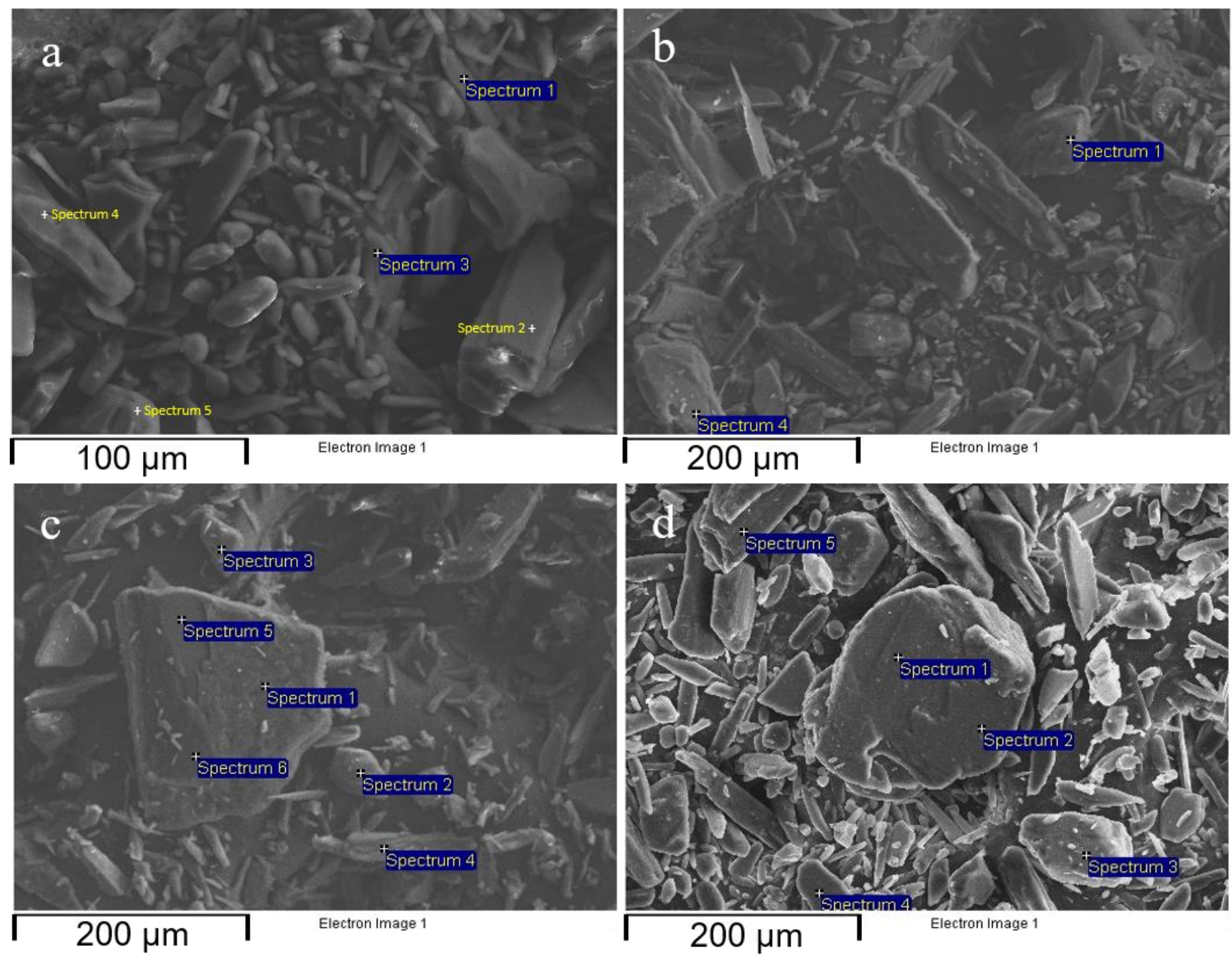

Figure 7. SEM images of point spectrum collected from a) 50 cycles $\mathrm{ALD} \mathrm{Al}_{2} \mathrm{O}_{3}$ coated acetaminophen sample, b) 50 cycles $\mathrm{ALD} \mathrm{TiO}_{2}\left(\mathrm{TiCl}_{4}\right)$ coated acetaminophen sample, c) 50 cycles $\mathrm{TiO}_{2}$ (TTIP) coated acetaminophen sample, and d) 50 cycles $\mathrm{ZnO}$ coated acetaminophen sample by SEM with EDS.

The area pointed to by spectrum 5 is very smooth representing plane acetaminophen surface similarly to images in Figure 5a and $\mathbf{5 b}$ for acetaminophen without ALD coating, while the areas on the same particle pointed to by the spectra 1 and 6 appear rougher. EDS elemental mapping across the particle cross-sections shown in Figure $\mathbf{2 S}$ reveals that the X-rays originating from the coating material $\left(\mathrm{Al} \mathrm{Ka}\right.$ in $\mathrm{Al}_{2} \mathrm{O}_{3}$ and $\mathrm{Ti} \mathrm{Ka}$ in $\left.\mathrm{TiO}_{2}\right)$ are localized on areas close to the top surface 
of the ACTM particle, thus confirming the presence of the film on the surface of the particle. Al or $\mathrm{Ti}$ signals were not observed in the interior of the particles, showing that the average composition of the ACTM particle is not modified by the coating. The area under spectrum 5 in Figure 7c is attributed to be a fracture surface caused by splitting along the crystal plane resulting in a very smooth surface. A higher resolution image of Figure 7c (point spectrum for TTIP) shown in Figure $\mathbf{8}$ can be used as a reliable means to study the morphological difference between the uncoated and the ALD oxide coated acetaminophen surface. The fracture surface is very smooth as can be expected for a split surface of the crystal, whereas the ALD coated surface appears to be relatively rough. Since ALD films tend to grow conformally and uniformly regardless of surface topography, this rougher surface may indicate changes on the acetaminophen due to the reaction during the initial ALD film growth. A closer look at the images shown in Figures $\mathbf{5 b}, \mathbf{d}, \mathbf{f}, \mathbf{h}$ and j reveals localized changes on the otherwise smoothly appearing surface. These changes indicated inside the black circles appear as attached crystals growing from the surface and can be distinguished from the smaller looser particles attached on the surface.

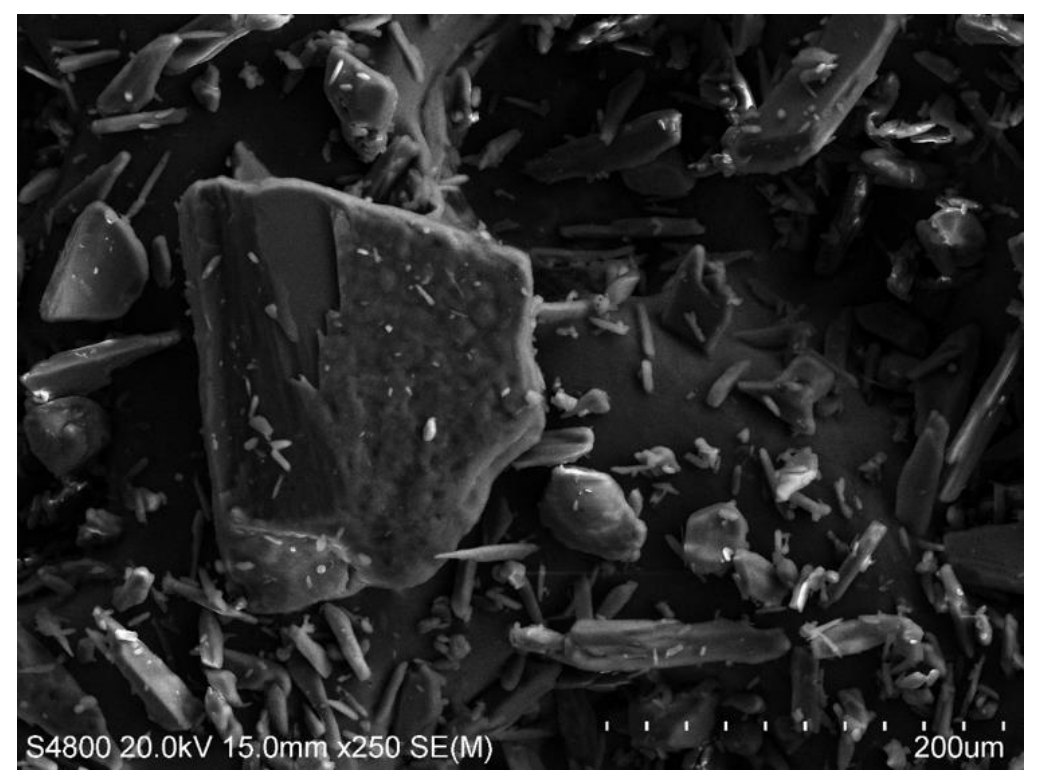

Figure 8. SEM image of 50 cycles $\mathrm{ALD} \mathrm{TiO}_{2}$ (TTIP) coated acetaminophen sample. 
In earlier work where acetaminophen was mixed with sodium caseinate and lecithin in distilled water and then spray dried at $130{ }^{\circ} \mathrm{C}$ (spray outlet temperature $75^{\circ} \mathrm{C}$ ), the attached crystals on the particle surface were attributed to the crystallization of the drug onto the surface (Thi et al., 2012). In our study, the crystallization of acetaminophen on the particle surface would require amorphization of crystalline drug during the deposition. Based on XRD, the acetaminophen remains crystalline during the deposition so the possible amorphization takes place on the surface of the crystalline particles, which is not detected by XRD (Figure S1). Change in acetaminophen particle surface roughness has also been observed after leucine dry powder coating (Ghoroi et al., 2013).

\subsection{Stability after ALD Coating}

HPLC chromatograms of the working solution of acetaminophen and ALD coated acetaminophen samples are presented in Figure 9. The elution time for acetaminophen detected from all the samples by UV-Vis at the wavelength of $230 \mathrm{~nm}$ was $2.30 \mathrm{~min}$. The process-related organic impurities of acetaminophen have been studied and identified by using an HPLC method; they can result from the poor quality of starting materials, reagents and solvents, the reaction conditions and the design of the process equipment (Kamberi et al., 2004; Calinescu et al., 2012). The chromatograms of uncoated acetaminophen and ALD coated acetaminophen in Figure 9 show that there are no ALD initiated degradation products identified for acetaminophen on any of the ALD coated samples studied. 


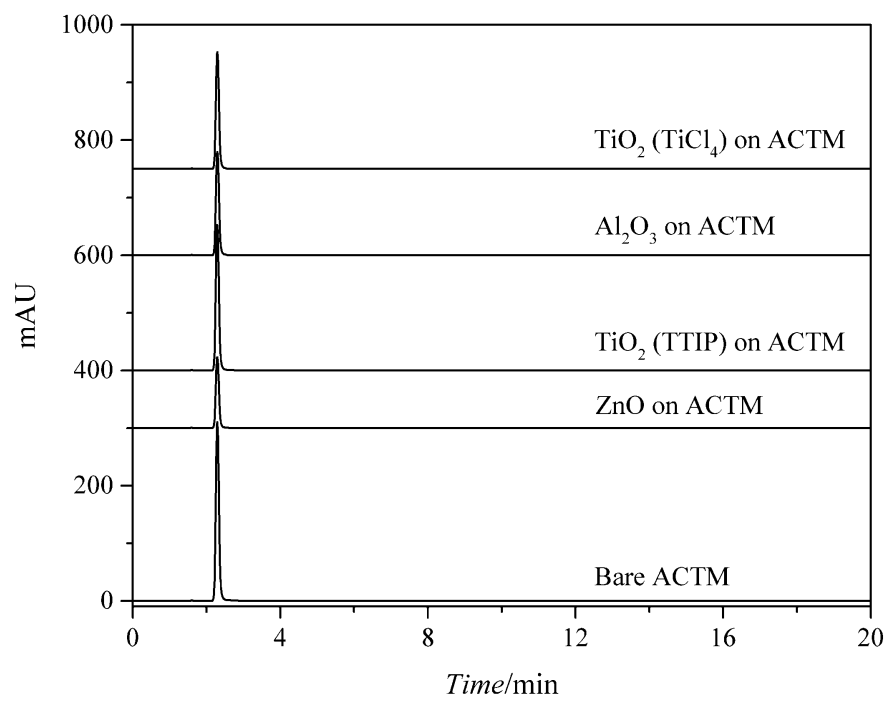

Figure 9. Chromatograms of acetaminophen and 50 cycles ALD oxide coated acetaminophen samples in working solution. Peak 1 , acetaminophen.

\subsection{Drug Release Studies}

Release profiles of bare acetaminophen and ALD coated acetaminophen samples determined in PBS at pH of 6.8 and buffer solution at pH of 1.2 are shown in Figure 10. The inset graphs in both Figures show the drug release during the first 30 min of dissolution. Bare acetaminophen dissolved in the solution at $\mathrm{pH} 6.8$ after 2 min dissolution time, while all the ALD coated acetaminophen samples appear to sustain the drug release for longer. $\mathrm{ZnO}$ coated acetaminophen seems to have the most prolonged drug release profile at $\mathrm{pH} 6.8$ with around $83 \%$ released drug content after a dissolution time of $6 \mathrm{~h}$. The release profiles in Figure 10b reveal very fast release of acetaminophen for all samples at $\mathrm{pH}$ 1.2. The first measurement points after 2 min dissolution (Figure 10b) suggest some degree of sustained drug release for both $\mathrm{Al}_{2} \mathrm{O}_{3}$ and $\mathrm{TiO}_{2}$ coated samples. $\mathrm{Al}_{2} \mathrm{O}_{3}$ coated acetaminophen samples prolong the drug release up to 15 to 20 min at which point the release profile reaches a plateau. This is attributed to a thicker $\mathrm{Al}_{2} \mathrm{O}_{3}$ film. 

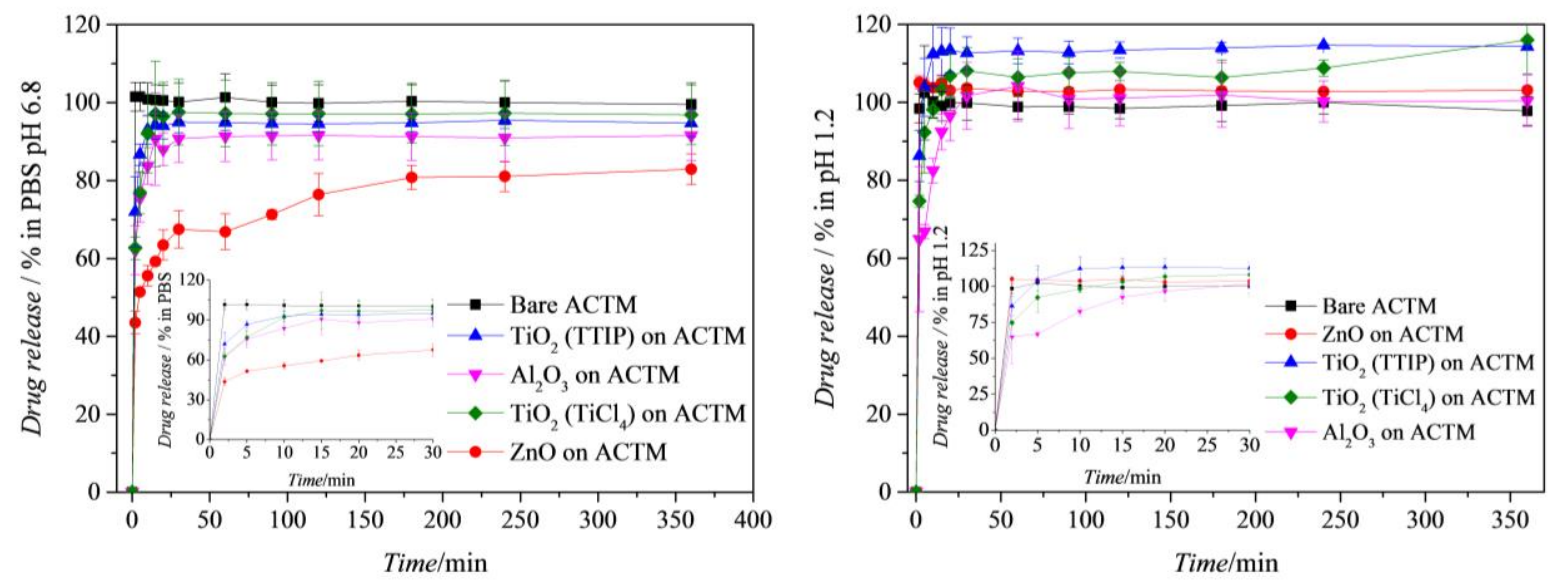

Figure 10. Drug release profiles of uncoated acetaminophen and 50 ALD cycles oxide coated acetaminophen samples in PBS at pH 6.8 (a), and in buffer solution at pH 1.2 (b).

\subsection{Cell viability and ROS production}

Conferring new surface properties to APIs can modify their flowability, dispersibility and aqueous dissolution profile, but can also alter their compatibility towards living tissues. In the case of metal oxides, which are currently used in many fields such as consumer products and biomedical applications and, therefore, prone to exposure to human tissue, it is of paramount importance to investigate the biological effects of such exposure. The incubation of $\mathrm{TiO}_{2}\left(\mathrm{TiCl}_{4}\right)$ ALD acetaminophen powder with the human intestinal Caco-2 cells showed that these powders did not induce any statistically significant toxicity in the concentrations and incubations times tested (Figure 11a). In contrast, $\mathrm{ZnO}$ ALD acetaminophen powder induced a very pronounced toxic effect across all tested concentrations and incubation times, with the exception of $15 \mu \mathrm{g} \mathrm{ml}^{-1}$ at 24h (Figure 11b). In addition, $\mathrm{Al}_{2} \mathrm{O}_{3}$ and $\mathrm{TiO}_{2}$ (TTIP) ALD acetaminophen powders were also assessed for cellular viability and displayed moderate to high toxicity (between $46 \%$ and $88 \%$ cell viability) in Caco-2 cells at 24h (Figure S3). The viability results indicate that the ALD coatings with the most cytocompatibility are, in descending order, $\mathrm{TiO}_{2}\left(\mathrm{TiCl}_{4}\right), \mathrm{Al}_{2} \mathrm{O}_{3}, \mathrm{TiO}_{2}$ (TTIP) and 
$\mathrm{ZnO}$. Metal oxides, especially in the form of nanoparticles, have been found to lead to the formation of ROS in cells with deleterious effects on cell viability. Usually the first marker of oxidative aggression, ROS can lead towards inflammation and ultimately cytotoxicity (Nel et al., 2006). As such, we subsequently investigated ROS generation in Caco- 2 cells by $\mathrm{TiO}_{2}\left(\mathrm{TiCl}_{4}\right)$ and $\mathrm{ZnO}$ at 3,6 and $24 \mathrm{~h}$ and found that none of these ALD acetaminophen powders induced any statistically significant ROS across all concentrations and time points tested (Figure $10 \mathbf{c}$ and d). It is worth mentioning that $\mathrm{ROS}$ generation induced by $\mathrm{ZnO}$ nanoparticles has been found to be surface- and cell-type dependent (Hanley et al., 2009; Jeong et al., 2013; Moos et al., 2010) and that $\mathrm{ZnO}$-induced toxicity has also been suggested not to be dependent on either the classical extrinsic or mitochondrial signaling pathway, but rather, a caspase-independent alternative apoptosis signaling mechanism, in which ROS is not a major contributor (Buerki-Thurnherr et al., 2013).
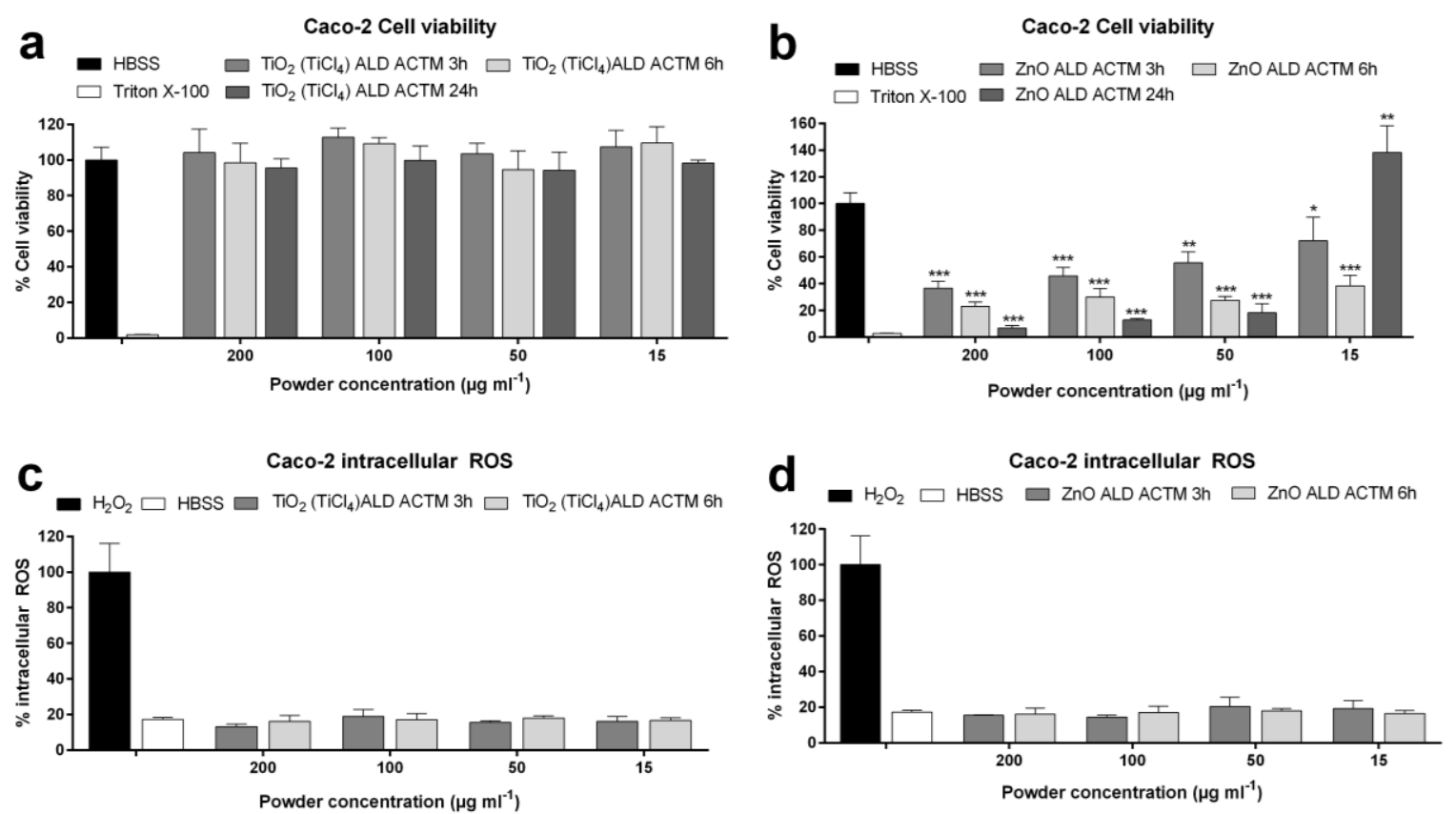

Figure 11. Cell viability ( $a$ and $b$ ) and intracellular ROS assessment (c and d) of the human epithelial colorectal adenocarcinoma Caco-2 cells after exposure to ALD oxide coated acetaminophen powders with the concentration of 200, 100, 50 and $15 \mu \mathrm{g} \mathrm{ml}^{-1}$ in HBSS for 3, 6 
and $24 \mathrm{~h}$. Statistical analysis was made by ANOVA, followed by a Dunnett's multiple comparison test. The level of significance was set at a probability of $\mathrm{p}<0.05$ for $*$, $\mathrm{p}<0.01$ for $* *$, and $\mathrm{p}<$ 0.001 for $* * *$. Error bars represent SD $(\mathrm{n} \geq 3)$.

Finally, the inflammatory response measured by TNF- $\alpha$ release from Caco- 2 cells incubated with the ALD powder which gave the highest toxicity $(\mathrm{ZnO})$ was also investigated. No statistically significant TNF- $\alpha$ induction was detected in the concentrations and incubation times tested (Figure 11), which is corroborated by several reports that have shown that cytotoxic concentrations of $\mathrm{ZnO}$ do not elicit a broad inflammatory response, measured by increased TNF$\alpha$ expression levels (Moos et al., 2011; Roselli et al., 2003).

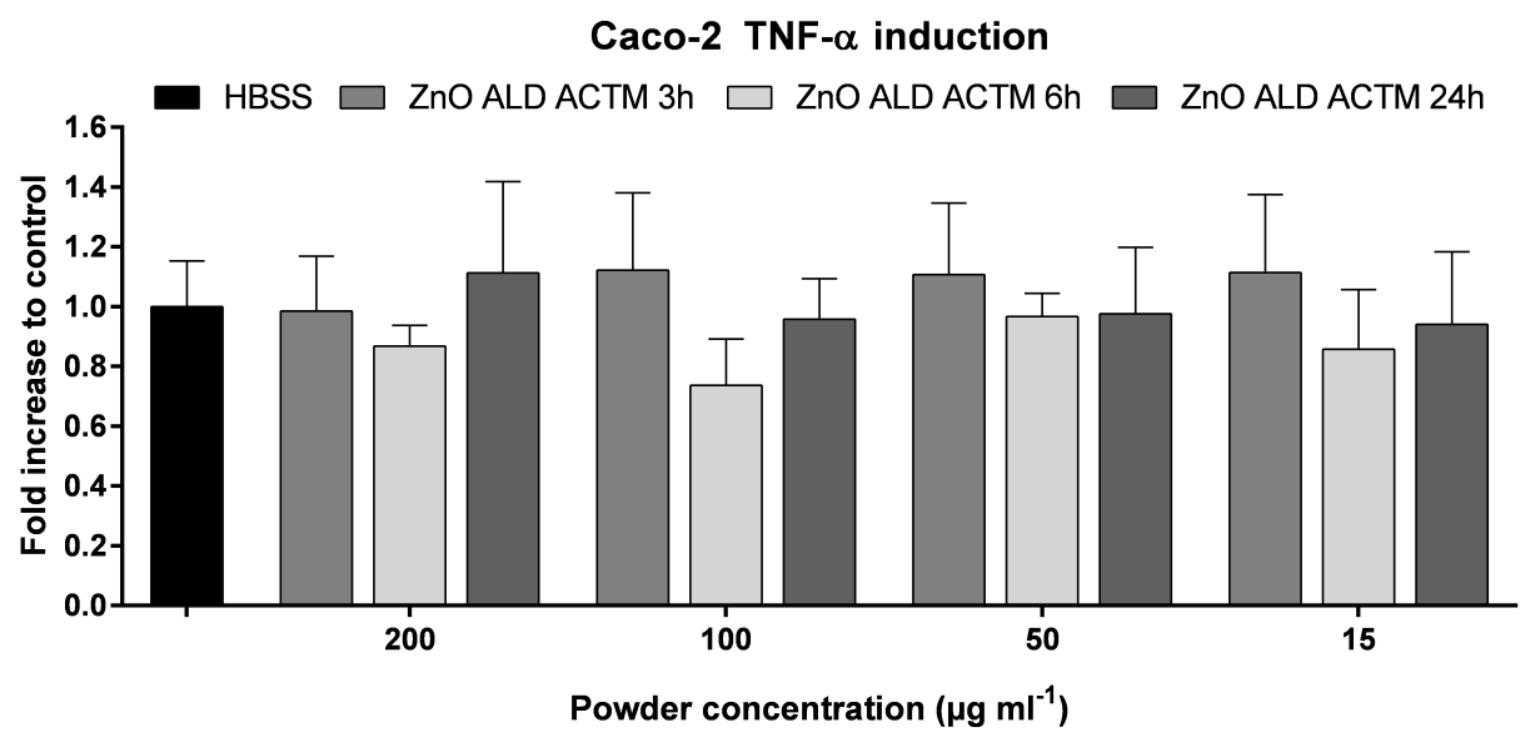

Figure 12. TNF- $\alpha$ assessment of the human epithelial colorectal adenocarcinoma Caco-2 cells after 3, 6 and $24 \mathrm{~h}$ incubation with the different concentrations of ALD ZnO coated acetaminophen powder samples. Statistical analysis was made by ANOVA, followed by a Dunnett's multiple comparison test. All the data sets were compared with a positive control of HBSS. The level of significance was set at probabilities of $* p<0.05,{ }^{* *} p<0.01$, and $* * * p<0.001$. Error bars represent mean $\pm \mathrm{SD}(n \geq 3)$. 


\section{CONCLUSION}

Atomic layer deposition (ALD) was used to demonstrate the feasibility of the coating method directly onto solid drug particles, and provide the proof of concept by using acetaminophen as a model API. The results show that the initial polymorph of acetaminophen (form I) remains as the main polymorph during and after the ALD oxide deposition. $\mathrm{ALD}-\mathrm{TiO}_{2}$ using $\mathrm{TiCl}_{4}$ and water chemistry resulted in the transformation of the acetaminophen surface to the mixed system of acetaminophen and ALD- $\mathrm{TiO}_{2}$, while keeping the main component of the coated acetaminophen as monoclinic form I. HPLC analysis indicated no degradation products of acetaminophen for the ALD coated samples for the ALD chemistries studied. The different metal oxides deposited on acetaminophen powders displayed different cytocompatibility profiles, with $\mathrm{TiO}_{2}\left(\mathrm{TiCl}_{4}\right)$ being cytocompatible and $\mathrm{ZnO}$ eliciting the most cytotoxicity among the ALD materials under study. Oxidative stress induced by $\mathrm{TiO}_{2}\left(\mathrm{TiCl}_{4}\right)$ and $\mathrm{ZnO}$ ALD powders and inflammatory response measured for $\mathrm{ZnO}$ was found not to be statistically significant across all concentrations and time points tested. The results presented herein show that, under controlled conditions, ALD is a sensitive surface driven method, providing conformal surface modification and ultrathin encapsulation of solid active pharmaceutical particles. ALD coatings can therefore be used to improve drug release profile, optimize drug loading efficiency, stabilize active pharmaceutical particles prior to further processing and control their responsive behavior. ALD is an enticing coating technology to be used in development of advanced drug delivery systems and platforms for oral drug delivery applications. 


\section{ASSOCIATED CONTENT}

Supporting Information. Supporting information is available on the Elsevier website.

\section{ACKNOWLEDGMENTS}

Dr. T. O. Kääriäinen acknowledges financial support from the Academy of Finland (decision number 278968). Dr. H. A. Santos acknowledges financial support from the Academy of Finland (decision nos. 252215 and 281300), the University of Helsinki Research Funds, the Biocentrum Helsinki, and the European Research Council under the European Union's Seventh Framework Programme (FP/2007-2013, Grant No. 310892). Dr. L. M. Bimbo acknowledges financial support from the Academy of Finland (decision number 276377), the Finnish Cultural Foundation, Orion Research Foundation, Biocentrum Helsinki, and the Jane and Aatos Erkko Foundation. 


\section{REFERENCES}

Aarik, J., Aidla, A., Uustare, T., Ritala, M., Leskelä, M., 2000. Titanium isopropoxide as a precursor for atomic layer deposition: characterization of titanium dioxide growth process. Appl. Surf. Sci. 161, 385-395.

Airaksinen, S., Karjalainen, M., Shevchenko, A., Westermarck, S., Leppänen, E., Rantanen, J., Yliruusi, J., 2005. Role of water in the physical stability of solid dosage formulations. J. Pharm. Sci. 94, 2147-2165.

Beach, L., Ropero, J., Mujumdar, A., Alcalà, M., Romanach, R. J., Davé, R. N., 2010. NearInfrared Spectroscopy for the In-Line Characterization of Powder Voiding Part II: Quantification of Enhanced Flow Properties of Surface Modified Active Pharmaceutical Ingredients. J. Pharm. Innov. 5, 1-13.

Behzadi, S. S., Toegel, S., Viernstein, H., 2008. Innovations in coating technology. Recent Pat. Drug Deliv. Formul. 2, 209-230.

Bimbo, L. M., Mäkilä, E., Laaksonen, T., Lehto, V. -P., Salonen, J., Hirvonen, J., Santos, H.A., 2011. Drug permeation across intestinal epithelial cells using porous silicon nanoparticles. Biomaterials 32, 2625-2633.

Buerki-Thurnherr, T., Xiao, L., Diener, L., Arslan, O., Hirsch, C., Maeder-Althaus, X., Grieder, K., Wampfler, B., Mathur, S., Wick, P., Krug, H. F., 2013. In vitro mechanistic study towards a better understanding of $\mathrm{ZnO}$ nanoparticle toxicity. Nanotoxicology 7, 402-416. 
Calinescu, O., Badea, I. A., Vladescu, L., Meltzer, V., Pincu, E., 2012. HPLC separation of acetaminophen and its impurities using a mixed-mode reversed-phase/cation exchange stationary phase. J. Chromatograph. Sci. 50, 335-342.

Chen, R., Okamoto, H., Danjo, K., 2006. Particle design using a 4-fluid-nozzle spray-drying technique for sustained release of acetaminophen. Chem. Pharm. Bull. 54, 948-953.

Chow, A. H. L., Tong, H. H. Y., Chattopadhyay, P., Shekunov, B. Y., Particle Engineering for Pulmonary Drug Delivery. Pharm. Res. 24, 411-437.

Das, S., Paul, A., Chattopadhyay, A., 2013. Nanocrystalline p-hydroxyacetanilide (paracetamol) and gold core-shell structure as a model drug deliverable organic-inorganic hybrid nanostructure. Nanoscale 5, 9247-9254.

Dobry, D. E., Settell, D. M., Baumann, J. M., Ray, R. J., Graham, L. J., Beyerinck, R. A., 2009. A Model-Based Methodology for Spray-Drying Process Development. J. Pharm. Innov. 4, $133-142$.

Eerikäinen, H., Watanabe, W., Kauppinen, E. I., Ahonen, P. P., 2003. Aerosol flow reactor method for synthesis of drug nanoparticles. Eur. J. Pharm. Biopharm. 55, 357-360.

Ehlers, H., Räikkönen, H., Antikainen, O., Heinimäki, J., Yliruusi, J., 2009. Improving flow properties of ibuprofen by fluidized bed particle thin-coating. Int. J. Pharm. 368, 165-170.

Elam, J. W., George, S. M., 2003. Growth of $\mathrm{ZnO} / \mathrm{Al}_{2} \mathrm{O}_{3}$ Alloy Films Using Atomic Layer Deposition Techniques. Chem. Mater. 15, 1020-1028.

Ferguson, J. D., Weimer, A. W., George, S. M., 2000. Atomic layer deposition of ultrathin and conformal $\mathrm{Al}_{2} \mathrm{O}_{3}$ films on $\mathrm{BN}$ particles. Thin Solid Films 371, 95-104. 
Ferguson, J. D., Weimer, A. W., George, S. M., 2004. Atomic layer deposition of $\mathrm{Al}_{2} \mathrm{O}_{3}$ films on polyethylene particles. Chem. Mater. 16, 5602-5609.

Ferguson, J. D., Yoder, A. R., Weimer, A. W., George, S. M., 2004. $\mathrm{TiO}_{2}$ atomic layer deposition on $\mathrm{ZrO} 2$ particles using alternating exposures of $\mathrm{TiCl}_{4}$ and $\mathrm{H}_{2} \mathrm{O}$. Appl. Surf. Sci. 226, 393-404.

Ghoroi, C., Han, X., To, D., Jallo, L., Gurumurthy, L., Davé, R. N., 2013. Dispersion of fine and ultrafine powders through surface modification and rapid expansion. Chem. Eng. Sci. 85, 11-24.

Giri, T. K., Kumar, K.; Alexander, A.; Ajazuddin, Badwaik, H., Tripathi, D. K., 2012. A novel and alternative approach to controlled release drug delivery system based on solid dispersion technique. Bull. Fac. Pharm. Cairo Univeristy. 50, 147-159.

George, S. M., 2010. Atomic layer deposition: An overview. Chem. Rev. 110, 111-131.

Hakim, L. F., Blackson, J., George, S. M., Weimer, A. W., 2005. Nanocoating individual silica nanoparticles by atomic layer deposition in a fluidized bed reactor. Chem. Vap. Deposition 11, $420-425$.

Han, J., Suryanarayanan, R., 1999. A method for the rapid evaluation of the physical stability of pharmaceutical hydrates. Thermochim. Acta 329, 163-170.

Hanley, C., Thurber, A., Hanna, C., Punnoose, A., Zhang, J., Wingett, D. G., 2009. The influences of cell type adn $\mathrm{ZnO}$ nanoparticle size on immune cell cytotoxicity and cytokine induction. Nanoscale Res. Lett. 4, 1409-1420.

Hoashi, Y., Tozuka, Y., Takeuchi, H., 2013. Solventless dry powder coating for sustained drug release using mechanochemical treatment based on the tri-component system of acetaminophen, carnauba wax and glidant. Drug Dev. Ind. Pharm. 39, 259-265. 
Huang, Y., Dai, W-G., 2014. Fundamental aspects of solid dispersion technology for poorly soluble drugs. Acta Pharm. Sin. B. 4, 18-25.

Hyde, G. K., Park, K. J., Stewart, S. M., Hinestroza, J. P., Parsons, G. N., 2007. Atomic Layer Deposition of conformal inorganic nanoscale coatings on three-dimensional natural fiber systems: effect of surface topology on film growth characteristics. Langmuir 23, 9844-9849.

Höhne, G., Hemminger, W., Flammersheim, H.-J., 1996. Differential scanning calorimetry: An introduction for practioners, Springer-Verlag.

Jallo, L. J., Dave, R. N., 2015. Explaining electrostatic charging and flow of surface-modified acetaminophen powders as a function of relative humidity through surface energetics. Pharm. Drug Deliv. Pharm. Technol. 104, 2232-2232.

Jeong, S. H., Kim, H. J., Ryu, H. J., Ryu, W. I., Park, Y-H., Bae, H. C., Jang, Y. S., Son, S. W., 2013. $\mathrm{ZnO}$ nanoparticles induce TNF- $\alpha$ expression via ROS-ERK-Egr-1 pathway in human keratinocytes. J. Dermatol. Sci. 72, 263-273.

Johnson, R. W., Hultqvist, A., Bent, S. F., 2014. A brief review of atomic layer deposition: from fundamentals to applications. Materials Today 17, 236-246.

Kaialy, W., Larhrib, H., Chikwanda, B., Shojaee, S., Nokhodchi, A., 2014. An approach to engineer paracetamol crystals by antisolvent crystallization technique in presence of various additives for direct compression. Int. J. Pharm. 464, 53-64.

Kamberi, M., Riley, C. M., Ma (Sharon), X., Huang, C-W. C., 2004. A validated, sensitive HPLC method for the determination of trace impurities in acetaminophen drug substance. J. Pharm. Biomed. Anal. 34, 123-128. 
King, D. M., Liang, X., Zhou, Y., Carney, C. S., Hakim, L. F., Li, P., Weimer, A. W., 2008. Atomic layer deposition of $\mathrm{TiO} 2$ films on particles in a fluidized bed reactor. Powder Technol. $183,356-363$.

King, D. M., Liang, X., Weimer, A. W., 2012. Functionalization of fine particles using atomic and molecular layer deposition. Powder Technol. 221, 13-25.

Klímová, K., Leitner, J., 2012. DSC study and phase diagrams calculation of binary systems of paracetamol. Thermochimica Acta 550, 59-64.

Knez, M., Kadri, A., Wege, C., Gösele, U., Jeske, H., Nielsch, K., 2006. Atomic layer deposition on biological macromolecules: Metal oxide coating of tobacco mosaic virus and ferritin. Nano Lett. 6, 1172-1177.

Knez, M., Kornelius, N., Niinistö, L., 2006. Synthesis and surface engineering of complex nanostructures by atomic layer deposition. Adv. Mater. 19, 3425-3438.

Kääriäinen, T., Cameron, D. C., Kääriäinen, M-L., Sherman, A. 2013. Atomic layer deposition: Principles, characteristics and nanotechnology applications, $2^{\text {nd }}$ edition. WileyScrivener.

Laaksonen, T., Liu, P., Rahikkala, A., Peltonen, L., Kauppinen, E. I., Hirvonen, J., Järvinen, K., Raula, J., 2011. Intact nanoparticulate indomethacin in fast-dissolving carrier particles by combined wet milling and aerosol flow reactor methods. Pharm. Res. 28, 2403-2411.

Ledeti, I., Simu, G., Vlase, G., Savoiu, G., Vlase, T., Suta, L-M., Popoiu, C., Fulias, A., 2013. Synthesis and solid-state characterization of $\mathrm{Zn}$ (II) metal complex with acetaminophen. Rev. Chim. (Bucharest). 64, 1127-1130. 
Ledru, J., Imrie, C. T., Pulham, C. R., Céolin, R., Hutchinson, J. M., 2007. Pharmacokinetics, pharmacodynamics and drug metabolism: High pressure differential scanning calorimetry investigations on the pressure dependence of the melting of paracetamol polymorphs I and II. J. Pharm. Sci. 96, 2784-2794.

Longrie, D., Deduytsche, D., Detavernier, C., 2014. Reactor concepts for atomic layer deposition on agitated particles: A review. J. Vac. Sci. Technol. A. 32, 010802.

Matsuo, K., Matsuoka, M., 2007. Solid-state polymorphic transition of theophylline anhydrate and humidity effect. Cryst. Growth Des. 7, 411-415.

McCormick, J. A., Cloutier, B. L., Weimer, A. W., George, S. M., 2007. Rotary reactor for atomic layer deposition on large quantities of nanoparticles. J. Vac. Sci. Technol. A. 25, 67-74.

Miikkulainen, V., Leskelä, M., Ritala, M., Puurunen, R. L., 2013. Crystallinity of inorganic films grown by atomic layer deposition: Overview and general trends. J. Appl. Phys. 113, 021301(1-101).

Moos, P. J., Chung, K., Woessner, D., Honeggar, M., Cutler, N. S., Veranth, J. M., 2010. ZnO particulate matter requires cell contact for toxicity in human colon cancer cells. Chem. Res. Toxicol. 23, 733-739.

Moos, P. J., Olszewski, K., Honeggar, M., Cassidy, P., Leachman, S., Woessner, D., 2011. Responses of human cells to $\mathrm{ZnO}$ nanoparticles: a gene transcription study. Metallomics 3, 11991211.

Nel, A., Xia, T., Mädler, L., Li, N., 2006. Toxic potential of materials at the nanolevel. Science $311,622-627$. 
Nevalainen, K., Suihkonen, R., Eteläaho, P., Vuorinen, J., Järvelä, P., Isomäki, N., Hintze, C., Leskelä, M., 2009. Mechanical and tribological property comparison of melt-compounded nanocomposites of atomic-layer-deposition-coated polyamide particles and commercial nanofillers. J. Vac. Sci. Technol. A. 27, 929-936.

Park, D-H., Kim, J-E., Oh, J-M., Shul, Y-G., Choy, J-H., 2010. DNA Core@Inorganic Shell. J. Am. Chem. Soc. 132, 16735-16736.

Peltonen, L., Hirvonen, J., 2014. Drug nanocrystals and nanosuspensions in medicine, in: Torchilin (ed.), Handbook of Nanobiomedical Research, World Scientific, 169.

Qi, S., Avalle, P., Saklatvala, R., Craig, D. Q. M., 2008. An investigation into the effects of thermal history on the crystallization behaviour of amorphous paracetamol. Eur. J. Pharm. Biopharm. 69, 364-371.

Rahtu, A., Ritala, M., 2002. Reaction mechanism studies on titanium isopropoxide-water atomic layer deposition process. Chem. Vap. Dep. 8, 21-28.

Raula, J., Lähde, A., Kauppinen, E. I., 2008. A novel gas phase method for the combined synthesis and coating of pharmaceutical particles. Pharm. Res. 25, 242-245.

Raula, J., Rahikkala, A., Halkola, T., Pessi, J., Peltonen, L., Hirvonen, J., Järvinen, K., Laaksonen, T., Kauppinen, E. I., 2013. Coated particle assemblies for the concominant pulmonary administration of budesonide and salbutamol suphate. Int. J. Pharm. 441, 248-254.

Ritala, M., Leskelä, M., Niinistö, L., Haussalo, P., 1993. Titanium isopropoxide as a precursor in atomic layer epitaxy of titanium dioxide thin films. Chem. Mater. 5, 1174-1181. 
Roselli, M., Finamore, A., Garaguso, I., Britti, M. S., Mengheri, E., 2003. Zinc oxide protects cultured enterocytes from the damage induced by Escherichia coli. J. Nutr. 12, 4077-4087.

Rossi, A., Savioli, A., Bini, M., Capsoni, D., Massarotti, V., Bettini, R., Gazzaniga, A., Sangalli, M. E., Giordano, F., 2003. Solid-state characterization of paracetamol metastable polymorphs formed in binary mixtures with hydroxypropylmethylcellulose. Thermochimica Acta 406, 55-67.

Sacchetti, M., 2001. Thermodynamic analysis of DCS data for acetaminophen polymorphs. J. Thermal Anal. Calorimetry 63, 345-350.

Sauer, D., Cerea, M., DiNunzio, J., McGinity, J., 2013. Dry powder coating of pharmaceuticals: A review. Int. J. Pharm. 457, 488-502.

Sarnes, A., Østergaard, J., Jensen, S.S., Aaltonen, J., Rantanen, J., Hirvonen, J., Peltonen, L., 2013. Dissolution study of nanocrystal powders of a poorly soluble drug by UV imaging and channel flow methods. Eur. J. Pharm. Sci. 50, 511-519.

Schäfer, C., Schröder, K. R., Höglinger, O., Tollabimazraehno, S., Lornejad- Schäfer, M. R., 2013. Acetaminophen changes intestinal epithelial cell membrane properties, subsequently affecting absorption processes. Cell. Physiol. Biochem. 32, 431-447.

Shi, L., Sun, C. C., 2011. Overcoming poor tabletability of pharmaceutical crystals by surface modification. Pharm. Res. 28, 3248-3255.

Singh, R. K., Kim, W. S., Ollinger, M., Craciun, V., Coowantwong, I., Hochhaus, G., Koshizaki, N., 2002. Laser based synthesis of nanofunctionalized particulates for pulmonary based controlled drug delivery applications. Appl. Surf. Sci. 197-198, 610-614. 
Taylor, A. J., McClure, C. D., Shipkowski, K. A., Thompson, E. A., Hussain, S., Garantziotis, S., Parsons, G. N., Bonner, J. C., 2014. Atomic Layer Deposition Coating of Carbon Nanotubes with Aluminum Oxide Alters Pro-Fibrogenic Cytokine Expression by Human Mononuclear Phagocytes In Vitro and Reduces Lung Fibrosis in Mice In Vivo. PLOS ONE 9, e106870, 1-14.

Terracciano, M., Shahbazi, M-A., Correia A., Rea, I.; Lamberti, A., De Stefano, L., Santos, H. A., 2015. Surface bioengineering of diatomite based nanovectors for efficient intracellular uptake and drug delivery. Nanoscale 7, 20063-20074.

Thi, T. H. H., Morel, S., Ayouni, F., Flament, M-P., 2012. Development and evaluation of tastemasked drug for paediatric medicines - Application to acetaminophen. Int. J. Pharm. 434, 235242.

Trasi, N. S., Taylor, L. S., 2012. Effect of polymers on nucleation and crystal growth of amorphous acetaminophen. Cryst. Eng. Comm. 14, 5188-5197.

Van Ommen, J. R. 2010. Delft University of Technology, EP2403976.

Vanhoorne, V., Peeters, E., Van Snick, B., Remon, J. P., Vervaet, C., 2014. Crystal coating via spray drying to improve powder tabletability. Eur. J. Pharm. Biopharm. 88, 939-944.

Vartiainen, V., Bimbo, L. M., Hirvonen, J., Kauppinen, E. I., Raula, J., 2016. Drug permeation and cellular interaction of amino acid-coated drug combination powders for pulmonary delivery. Int. J. Pharm. 504, 89-97.

Vehring, R., 2008. Pharmaceutical particle engineering via spray drying. Pharm. Res. 25, 9991022. 
Werner, S. R. L., Jones, J. R., Paterson, A. H. J., Archer, R. H., Pearce, D. L., 2007. Airsuspension particle coating in the food industry: Part I - state of the art. Powder Technol. 171, 2533.

Wu, Y., Levons, J., Narang, A. S., Raghavan, K., Rao, V. M., 2011. Reactive impurities in excipients: Profiling, identification and mitigation of drug-excipient incompatibility. AAPS Pharm. Sci. Tech. 12, 1248-1263.

Zhao, M., Barker, S. A., Belton, P. S., C. McGregor, C., Craig, D. Q. M., 2014. Development of fully amorphous dispersions of a low $\mathrm{T}_{\mathrm{g}}$ drug via co-spray drying with hydrophilic polymers. Eur. J. Pharm. Biopharm. 82, 572-579.

Zimmerman, B., Baranovic, G., 2011. Thermal analysis of paracetamol polymorphs by FT-IR spectroscopies. J. Pharm. Biomed. Anal. 54, 295-302. 